\title{
HISTORY OF PHARMACOKINETICS
}

\author{
JOHN G. WAGNER \\ College of Pharmacy, Upjohn Center for Clinical Pharmacology, Medical School, \\ The University of Michigan, Ann Arbor, MI 48109, U.S.A.
}

\section{THE TERM AND ITS MEANING}

The term pharmacokinetics was first introduced by F. H. Dost in 1953 in his text, Der Blütspiegel-Kinetic der Konzentrationsablaüfe in der Frieslaufflüssigkeit (Dost, 1953). However, some of the subject matter was published before the word was coined. It is also of interest that the first English language review of the subject matter, published in 1961, was entitled the Kinetics of Drug Absorption, Distribution, Metabolism and Excretion and did not include the word pharmacokinetics (Nelson, 1961).

Pharmacokinetics has been defined in a number of ways. Literally, the word means the application of kinetics to pharmakon, the Greek word for drugs and poisons. Kinetics is that branch of knowledge which involves the change of one or more variables as a function of time. The purpose of pharmacokinetics is to study the time course of drug and metabolite concentrations or amounts in biological fluids, tissues and excreta, and also of pharmacological response, and to construct suitable models to interpret such data. In pharmacokinetics, the data are analyzed using a mathematical representation of a part or the whole of an organism. Broadly then, the purposes of pharmacokinetics are to reduce data to a number of meaningful parameter values, and to use the reduced data to predict either the results of future experiments or the results of a host of studies which would be too costly and time-consuming to complete (Wagner, 1968 and 1975). A similar definition has been given by other authors (Gibaldi and Levy, 1976) as follows: 'Pharmacokinetics is concerned with the study and characterization of the time course of drug absorption, distribution, metabolism and excretion, and with the relationship of these processes to the intensity and time course of therapeutic and adverse effects of drugs. It involves the application of mathematical and biochemical techniques in a physiologic and pharmacologic context.'

In this historical review emphasis is placed on pharmacokinetic theory and not on applications of that theory.

\section{ORIGINS OF THE SUBJECT MATTER}

The origins of the subject matter of pharmacokinetics are both multinational and multidisciplinary.

Buchanan in England in 1847, while describing ether anesthesia, clearly understood that the brain content of anesthetics determined the depth of narcosis and depended upon the arterial concentration, which in turn was related to the strength of the inhaled mixture. Moreover, he pointed out that for short ether inhalations, the speed of recovery was related to redistribution of ether in the body. He calculated the amounts of ether inhaled, exhaled and retained during induction with this short acting anesthetic (Buchanan, 1947; Butler, 1964).

From Germany, in 1913, Michaelis and Menten published what is now known as the Michaelis-Menten equation for describing enzyme kinetics. In pharmacokinetics, this same equation is used to describe the elimination kinetics of ethanol, salicylate, phenytoin and several other drugs (Michaelis and Menten, 1913). 
Swedish investigators, Widmark and Tandberg, in 1924 published equations appropriate to what are now called: (a) the one-compartment open model with bolus intravenous injection and multiple doses administered at uniform time intervals, and (b) the one-compartment open model with constant rate intravenous infusion (Widmark and Tandberg, 1924).

In the United States, Haggard, in the same year (1924), published his classical articles on the uptake, distribution and elimination of diethyl ether. He considered the distribution of ether on theoretical grounds and also showed that the drug in brain approached equilibrium more rapidly than drug in the body as a whole and that this was the result of the high proportional blood flow to brain (Haggard, 1924a-1924e; Butler, 1964). These articles have always been considered a part of the basic physiology literature, but it is obvious that they deal with the subject matter of pharmacokinetics as well. Other contributions of physiologists in the United States in the early years included those of Moller et al., of Jolliffee and Smith who introduced the concept of renal clearance and of Hamilton et al. who reported on studies of the intravascular transport an indicator such as a dye (Moller et al., 1929; Jolliffee and Smith, 1931; Hamilton et al., 1931). It was Hamilton et al. who introduced the following equations:

$$
\begin{aligned}
& V=\bar{t} Q \\
& \bar{t}=\frac{\int_{0}^{\infty} t C \mathrm{~d} t}{\int_{0}^{\infty} C \mathrm{~d} t} .
\end{aligned}
$$

In Eqns (1) and (2), $V$ is the volume of the system, $\bar{t}$ is the mean transit time, $Q$ is the blood flow, and $C$ is the indicator concentration in plasma at time $t$. The numerator of the right-hand side of Eqn (2) is the area under the first moment of the concentrationtime curve, while the denominator is the area under the concentration-time curve. Equation 2 has reappeared in pharmacokinetic articles published in 1978 and 1979 (Yamaoka et al., 1978, Benet and Galeazzi, 1979).

In 1932, Widmark theorized that, following ingestion of ethyl alcohol and its equilibration in body fluids, it disappears from the blood at a constant rate (zero-order elimination) (Widmark, 1932). Much later, Lundquist and Wolthers and Wagner et al. showed that with moderate doses of alcohol, its elimination from human blood obeyed Michaelis-Menten kinetics and not zero-order kinetics (Lundquist and Wolthers, 1953; Wagner et al., 1976a). The reasons for the misinterpretation of Michaelis-Menten kinetics as zero-order kinetics were discussed by Wagner (Wagner, 1973a).

During the period 1939 to 1950 , Dominquez in the United States made significant contributions with articles on the pharmacokinetics of creatinine, mannitol, xylose and galactose (Dominguez, 1934; Dominguez and Pomerene, 1934; Dominguez et al., 1935; Dominguez and Pomerene, 1944, 1945a,b; Dominguez et al., 1947a and 1947b; Dominguez, 1950). He introduced the concept of the volume of distribution and defined it as the hypothetical volume of body fluid dissolving the substance at the same concentration as that in plasma (Dominguez, 1934). Dominguez was also the first to derive and apply Eqn (3) to estimate the rate of absorption of a substance as a function of time. In Eqn (3), $\mathrm{d} A / \mathrm{d} t$ is the rate

$$
\frac{\mathrm{d} A}{\mathrm{~d} t}=V \frac{\mathrm{d} C}{\mathrm{~d} t}+V k C
$$

of absorption at time $t, V$ is the volume of distribution, $C$ is the plasma drug concentration at time $t$ and $k$ is the first-order elimination rate constant.

In 1937, Teorell, a Swedish physiologist and biophysicist, published two remarkable articles which many now attribute as being the foundations of modern pharmacokinetics (Teorell, 1937a,b). The model of Teorell was one of the first physiologically-based 
pharmacokinetic models. It comprised a five-compartment scheme representing the circulatory system, a drug depot, fluid volume, kidney elimination and tissue inactivation. Actual physiological volumes were used for the various regions of the model. For many years he was unaware that he had made significant contributions to what later came to be known as pharmacokinetics. However, at the Conference on Pharmacology and Pharmacokinetics, Problems and Perspectives held at the Fogerty International Center at the National Institutes of Health in Bethesda, Maryland, U.S.A. 1972, which he attended, Teorell's contributions were recognized.

Bioavailability theory and testing has become an important topic in pharmacokinetics. Bioavailability is a term used to indicate the measurement of both the relative amount of an administered drug that reaches the general circulation intact and the rate at which this occurs. In the early years, bioavailability was called physiological availability. The concept was introduced by Oser and his associates in 1945, and their experimental work involved measurement of the bioavailability of vitamins administered in tablet form relative to their bioavailability administered in solution form (Oser et al., 1945, Melnick et al., 1945).

The literature on the theory and application of isotopic (radioactive) tracers contributed much to compartmental modeling and this helped in the advance of pharmacokinetic theory. Here there were many contributors and I shall cite only some of the important articles (Solomon, 1949; Lax and Wrenshall, 1953; Reiner, 1953; Solomon, 1953; Hart, 1955; Robertson, 1957; Russell, 1958; Cornfield et al., 1960; Shore, 1961).

Lapp in France, in the period 1948-56, reported on a number of kinetic studies, principally involving excretion kinetics. Compounds he studied included salicylate, stovarsol, uric acid, arsenic, sulfur, chlorine, sodium, rubiazol C, quinine, a soluble bismuth compound, sulfisoxazole and $N^{\prime}$-acetylsulfisoxazole. He pointed out the application of kinetic data in therapeutics (Lapp, 1948, Lapp, 1949; Lapp, 1950a, Lapp, 1950b; Lapp and Speiser, 1950; Lapp and Lapp, 1952; Lapp, 1952; Lapp and Nicolay, 1954; Lapp and Scius, 1954; Lapp, 1956a; Lapp, 1956b).

In 1948, Boxer and Jelinek in the United States considered the kinetics of the rise and fall of streptomycin blood concentrations with repeated dosage. They derived the equations applicable to the maximum and minimum concentrations for the one-compartment open model with bolus intravenous injection when multiple doses are given at equal time intervals, but actually applied them to the case when streptomycin was administered intramuscularly (Boxer and Jelinek, 1948). During the next year, 1949, there were two other contributions from the United States. Goldstein published the first comprehensive review of the interaction between drugs and plasma proteins (Goldstein, 1949) and Gaudino published equations defining a two-compartment open model and applied them to inulin kinetics (Gaudino, 1949).

The Dutch School made initial contributions in 1950 when DeJong and Wijans and Van Gemert and Duyff discussed the mathematical relationships between the dosage regimen and the pharmacological response. These appear to be the first articles concerned with optimization of dosage regimens of drugs (DeJong and Wijans, 1950; Van Gemert and Duyff, 1950).

In 1951, Bray and his colleagues at the University of Birmingham in England, published the first of an extensive series of articles concerning the kinetics of formation of benzoic acid from benzamide, toluene, benzyl alcohol and benzaldehyde, and its conjugation with glycine and glucuronic acid (Bray et al., 1951).

In Germany, in 1953, Dost published the first edition of his book (Dost, 1953), discussed in the beginning of this chapter. Der Blütspiegel was an outstanding book for its time and fully covered the so-called one-compartment open model with its various forms of input. A revised edition of his book entitled Grundlagen der Pharmacokinetik was published in 1968 .

The year 1953, when Der Blütspiegel was published, marks an appropriate termination of the section on the Origins of the Subject Matter of pharmacokinetics. The next reasonably well-defined historical period appears to be from 1954 to 1961. During this period a 
few, but not many, of the articles actually concerned with subject matter in the area of pharmacokinetics used the term pharmacokinetics. The year 1961 was chosen to end this second historical period, since, during that year, the English language reviews of Nelson (Nelson, 1961) and Wagner (Wagner, 1961) were published and considerable acceleration in interest in pharmacokinetics occurred from that time onwards.

\section{THE PERIOD 1954-1961}

In 1954 Butler et al. published an important article concerning elimination, accumulation, tolerance and dosage schedules of phenobarbital. This drug has a long elimination half-life, varying from about 2-6 days in man, and they showed that when administered once a day, accumulation was still occurring on the twelfth day. They also showed that plasma drug concentration, during a day at steady state, rises to a peak and falls to a trough, even when the half-life of a drug is long. Many investigators appear not to recognize that the term steady-state concentrations does not mean constant or the same concentrations when drug is administered orally. When equal doses are administered at uniform time intervals the steady-state is characterized by the concentration, time profile reproducing itself between any two doses. If two or more doses are given each day at non-uniform time intervals (such as 0,6 and $12 \mathrm{hr}$ ), then the steady-state would be characterized by the concentration, time profile reproducing itself each day.

Studies of the kinetics of elimination of glucose from blood during and after a continuous intravenous infusion (Jokipii and Turpeinen, 1954), and of the rate of absorption of water from the stomach and small bowel of human beings (Scholar and Code, 1954), are considered part of the classic literature of physiology but are also important in pharmacokinetics. A parallel exists with an article concerning the volumes of distribution and clearance values of intravenously injected creatinine in the dog (Sapirstein et al., 1955). This study with creatinine is the first article where an intercompartmental clearance was mentioned and defined mathematically. Similarly, drug clearance (plasma clearance) was apparently first defined as the ratio of the intravenous dose to the area under the plasma concentration-time curve from zero to infinite time by Hoenig and Schück (Hoenig and Schück, 1956). Berman, who has made many important contributions to compartment model-building, made an early contribution with Schoenfeld (Berman and Schoenfeld, 1956). The importance of the apparent elimination half-life of a drug in terminating its action was emphasized by Swintosky and co-workers and by Butler (Swintosky et al., 1957; Butler, 1958).

During this period Brodie, then at the Laboratory of Chemical Pharmacology, National Heart, Lung and Blood Institute, National Institutes of Health, published some of his classic pharmacology articles, which are important in pharmacokinetics. These were his articles on the gastric secretion of drugs (Shore et al., 1957) and on the kinetics of penetration of drugs and other foreign compounds into brain and cerebrospinal fluid (Mayer et al., 1957; Brodie et al., 1960). Riegelman, at the School of Pharmacy, University of California, San Francisco, who has made many contributions to pharmacokinetics, initiated his publications in the area with an article on the kinetics of rectal drug absorption (Riegelman and Cromwell, 1958). One of the earliest articles showing a correlation between response and serum drug concentration reported a study of serum phenytoin concentrations as a function of dosage, the time required to reach steady-state concentrations and a correlation between phenytoin serum concentrations and the degree of electroencephalographic abnormality in patients with epilepsy (Schiller and Buchthal, 1958). Although not a part of the pharmacokinetic literature, the publication by Williams of an extensive compilation on metabolism of drugs and other organic compounds, was an important milestone and the information that the book contained was useful in pharmacokinetic studies (Williams, 1959).

Nelson, initially at the School of Pharmacy, University of California, San Francisco and later at the School of Pharmacy, State University of New York at Buffalo, made a number of important contributions to pharmacokinetics and biopharmaceutics. Prob- 
ably the most important of these was his demonstration of dissolution rate-controlled absorption of drugs (Nelson, 1959; Nelson and Schaldemose, 1959).

The concept that total body water could be divided into plasma, interstitial-lymph, dense connective tissue and cartilage, inaccessible bone water, transcellular and intracellular components later aided physiologically-based pharmacokinetic model-building (Edelman and Liebman, 1959). An elegant article on the pharmacokinetics of halothane anesthesia stimulated many studies on the uptake of halothane and other anesthetic agents (Duncan and Raventós, 1959). Duncan and Raventós reported that halothane in arterial blood reached steady state after about $1 \mathrm{hr}$ of anesthesia, although the brain, liver and fat continued to take up the anesthetic for many hours. During the elimination of halothane, its arterial blood concentration decreased logarithmically with a half-life of $14 \mathrm{~min}$. The venous blood concentration of halothane decreased rapidly at first, then followed its rate of decrease in the fatty tissues, with a half-life of $45 \mathrm{~min}$. Other important contributions during this period were: (a) publication of a fundamental integral equation (Stephenson, 1960); (b) introduction of a curve-fitting method based on polyexponential equations (Perl, 1960); and (c) introduction of the use of the analog computer for fitting and simulating pharmacokinetic data and in model building (Garrett et al., 1960; Wiegand and Taylor, 1960; Taylor and Wiegand, 1960).

During this period and later, both Nelson and Krüger-Thiemer attempted to consolidate pharmacokinetics into a single scientific discipline. Krüger-Thiemer, who worked for many years at the Forchungsinstitutes Borstel, Germany, was particularly interested in the theory and application of pharmacokinetics to dosage regimens of sulfonamides and antibiotics. He made a marked impression with his first English language paper concerning this subject (Krüger-Thiemer, 1960a), subsequently publishing many other articles in both German and English (Krüger-Thiemer, 1960b; Krüger-Thiemer, 1961; Krüger-Thiemer and Schlender, 1963; Krüger-Thiemer et al., 1966).

During the late 1950's Brodie and associates elaborated the $\mathrm{pH}$-partition hypothesis and discussed its application in the mechanism of absorption of drugs from the gastrointestinal tract (Schanker, 1960). Other contributions during this period were (a) the work of Jenne et al. on the interpretation of isoniazid and p-aminosalicylic acid concentrationtime curves (Jenne et al., 1960); (b) investigations of Wagner et al. with sustained release prednisolone formulations and their testing in the dog, in man and in vitro (Wagner et al., 1960); (c) the development by Jacquez et al. of physiologically-based pharmacokinetic models (Jacquez et al., 1960); (d) studies by Onchi and Asao on the absorption, distribution and elimination of diethyl ether in man (Onchi and Asao, 1961); (e) early work on the intestinal absorption of salicyclic acid by Japanese investigators (Nogami and Matsuzawa, 1961); and (f) the first of many articles by Levy on salicylates (Levy et al., 1961).

\section{THE FIRST GROWTH PERIOD, 1961-1972}

Subsequent text will indicate the scope of pharmacokinetics as well as pointing out minor and major landmarks in development of the theory of pharmacokinetics, along with some applications. As with any similar review there will be inadvertent omissions and possibly misplaced emphasis, but the author sincerely tried to be fair to everyone who has contributed to pharmacokinetic theory.

Biopharmaceutics may be defined as the study of the influence of formulation on the therapeutic activity of a drug product. It encompasses all possible effects of the dosage forms on biological response, and all possible physiologic factors which may affect the drug contained in the dosage form and the dosage form of the drug itself (Wagner, 1971). In 1961 the author published a review article entitled: Biopharmaceutics: Absorption Aspects which caught the eye of many pharmaceutical and other scientists (Wagner, 1961). This review, along with that of Nelson (Nelson, 1961), resulted in a marked rise in interest in pharmacokinetics. During this period, a number of books in the area of pharmacokinetics appeared. These are listed in Table 1.

In 1962, Pharmakokinetik und Arzniemitteldosierung, the first symposium with a title 
TABle 1. Books Dealing with Pharmacokinetic Principles Published between 1961-1972

The Mathematical Approach to Physiological Problems (Riggs, 1963)

Uptake and Distribution of Anesthetic Agents (Papper and Kitz, 1963)

Pharmacogenetics (Kalow, 1965)

Drug and Tracer Kinetics (Rescigno and Segré, 1966)

Grundlagen der Pharmacokinetik (Dost, 1968)

Multicompartment Models for Biological Systems (Atkins, 1969)

Biopharmaceutics and Relevant Pharmacokinetics (Wagner, 1971a)

Biopharmaceutics and Pharmacokinetics: An Introduction (Notari, 1971)

Guidelines for Biopharmaceutical Studies in Man (Dittert et al., 1972)

Schering Workshop on Pharmacokinetics (Raspé, 1970)

Tracer Methods for In Vivo Kinetics: Theory and Applications (Shipley and Clark, 1972)

incorporating the term pharmacokinetics, was held in Borstel, Germany. The proceedings of this symposium were subsequently published in volume 12 of Antibiotica and Chemotherapia. The book and the symposium were potent forces in disseminating pharmacokinetic knowledge.

Publishing in the endocrinology area in 1963, Tait wrote a clear exposition of the meaning of clearance (metabolic clearance rate) and its relationship to hepatic blood flow, as well as the effect of postural changes on effective hepatic blood flow (Tait, 1963). It was not until ten years later that Rowland et al. made significantly greater use of the clearance concept (Rowland et al., 1973).

A method of estimating the amount of drug absorbed per milliliter of the volume of distribution versus time from either blood (serum or plasma) concentration-time data or urinary excretion data, based upon the one-compartment open model, later came to be known as the Wagner-Nelson method (Wagner and Nelson, 1963). An analogous method, based on the two-compartment open model, was later called the Loo-Riegelman method (Loo and Riegelman, 1968).

The representation of certain mammillary $N$-pool systems by two-pool models was the subject of an interesting article published in 1964 (Shaney et al., 1964). The problem of vanishing exponential terms in polyexponential equations was again treated considerably later (Wagner, 1976a; Ronfeld and Benet, 1977). These theoretical articles suggested that, if a panel of subjects were administered the same dose of drug by the same route of administration and the resulting blood (serum or plasma) concentration-time data were fitted by polyexponential equations with the statistically optimum number of terms per data set, different subjects would require different numbers of terms. Experimental verification of this prediction came with the data of Kalow and co-workers (Endrenyi et al., 1976). They administered an intravenous dose of $125 \mathrm{mg}$ of sodium amobarbital to seven pairs of identical twins and to seven pairs of fraternal twins. Blood samples were taken at uniform intervals and plasma was analyzed for amobarbital by a GLC method. Concentration-time data were fitted via a nonlinear estimation program and a digital computer to polyexponential equations where the optimum number of terms was decided by a statistical F-test. Results are shown in Table 2 . These results may be attributed to the relative magnitudes of the coefficients and exponents characterizing the curves of the

TABle 2. Results of Computer Fitting Amobarbital Plasma Concentration-Time Data (Endryi et al., 1976)

\begin{tabular}{|c|c|c|}
\hline $\begin{array}{l}\text { Optimum number of } \\
\text { exponential terms }\end{array}$ & Number of subjects & $\begin{array}{l}\text { Percentage of } \\
\text { subjects }\end{array}$ \\
\hline 1 & $5^{*}$ & 18 \\
\hline 2 & 16 & 57 \\
\hline 3 & 7 & 25 \\
\hline Total & $\overline{28}$ & $\overline{100}$ \\
\hline
\end{tabular}

*One of these 5 subjects gave only one exponential term on each of three different occasions. 
various subjects. The authors stated: 'Variability in the number of detectable exponential terms (emphasis being given to the word 'detectable') does not necessarily imply that, in different subjects, the disposition of amobarbital is characterized by differing numbers of compartments.' The author of this chapter now thinks it is much preferred to speak or write about monoexponential, biexponential and triexponential equations rather than one, two or three compartment open models.

Several reviews were published during this period. One covered the stimulatory effect of chronic drug administration on drug-metabolizing enzymes in liver microsomes (Burns et al., 1963)-which has implications in pharmacokinetics. Another dealt with the pharmacokinetics of halothane and ether (Butler, 1964). The third was titled Pharmacokinetics and was the first time this topic was covered in Annual Reviews of Pharmacology (Wagner, 1968b). In this period, an interest in pharmacokinetic drug interactions began with the report of the effect of phenobarbital on lowering plasma concentrations of both bishydroxycoumarin and phenytoin (Cucinell et al., 1965).

Beckett and Rowland related diurnal urine $\mathrm{pH}$ variations with $\mathrm{pH}$-dependent renal clearance of a drug. This article led to a large body of research which had implications in therapy, in drug product evaluation using urinary excretion data, in basic research, and in tests for 'doping' in sport (Beckett and Rowland, 1965).

The articles of Levy (Levy and Nelson, 1965; Levy, 1966; Levy et al., 1969; Nagashima et al., 1969) considered the kinetics of pharmacologic response and brought into focus relationships between intensity and duration of a pharmacologic response and the plasma drug concentration.

The simultaneous fitting of blood norepinephrine-time data and blood pressure-time data by Segré was also an advance in this important area of pharmacokinetics (Segré 1968). A logarithmic-logistic equation was also suggested to relate intensity of response to blood concentrations (Wagner, 1968a).

In 1965 Wagner et al. published a simple equation to estimate time-average steady state (blood, serum, or plasma) concentrations, $C_{\mathrm{av}}$, from the availability factor, $F$, the dose, $D$, given every $\tau \mathrm{hr}$, the volume of distribution, $V$, and the apparent elimination rate constant, $k$, as shown in Eqn (4). At the time of its publication this equation was referenced to the one-compartment open model. Gibaldi and Weintraub later showed that in multicompartment systems Eqn (4) could be written as Eqn (5) where $\lambda_{z}$ is the terminal exponential coefficient and the product $V \lambda_{\mathrm{Z}}$ is the clearance (Gibaldi and Weintraub, 1971). Still later Perrier

$$
\begin{aligned}
& C_{\mathrm{av}}=\frac{F D}{V k \tau} \\
& C_{\mathrm{av}}=\frac{F D}{V \lambda_{\mathrm{z}} \tau}
\end{aligned}
$$

and Gibaldi showed that one must multiply both sides of Eqn (5) by the volume of distribution steady state, $V_{\mathrm{ss}}$, to obtain the amount of drug in the body for a multicompartmental system (Perrier and Gibaldi, 1973).

It was during this period that pharmacokinetic articles which had a considerable impact on therapeutics began to appear and clinical pharmacokinetics was really 'born'. Noteworthy were the articles of Dettli on drug accumulation and dosage in patients with impaired renal function (Dettli et al., 1967; Dettli, 1970); of Jelliffe on digoxin dosage (Jeliffe, 1968); of Orme and Cutler who correlated kanamycin clearance with creatinine and inulin clearances (Orme and Cutler, 1969; Cutler and Orme, 1969); of Nagashima et al. on the anticoagulant action of warfarin (Nagashima et al., 1969); and that of Levy on the non-linear elimination kinetics of salicylate (Levy et al., 1972).

It was also during this period that Garrett further illustrated the usefulness of the analog computer (Garrett and Lambert, 1966) and Berman published details of his nonlinear estimation program, called SAAM, to be used in model-building with large digital computers (Berman and Weiss, 1966). 
The mathematics of the rate of drug accumulation in the one-compartment open linear system was apparently first considered in 1968 (Wagner and Northam, 1968; Van Rossum, 1968). A year later, exact solutions were given for the number of doses required to reach various percentages of the steady state value for the one and two-compartment open model with first-order absorption (Wagner and Northam, 1968: Wagner, 1969).

Physiologically-based models were introduced to describe the handling of drugs by the artificial kidney (Dedrick and Bischoff, 1968), as well as the pharmacokinetics of thiopental (Bischoff and Dedrick, 1968) and methotrexate Bischoff et al., 197!).

The years 1967-1969 also provided many theoretical articles which later became part of classical pharmacokinetics. These articles included: (a) a new method of estimating drug bioavailability (Wagner, 1967); (b) shortcomings in pharmacokinetic analysis by conceiving the body to exhibit properties of a single compartment (Riegelman et al., 1968 a); (c) the relationship between drug concentration and amount of drug in the body (Gibaldi et al., 1969); (d) the influence of route of administration on the area under the plasma concentration-time curve (Harris and Riegelman, 1969; Gibaldi and Feldman, 1969); (e) the effect of mode of administration on drug distribution in a two-compartment open system (Gibaldi, 1969); (f) volume terms in pharmacokinetics (Ronfeld and Benet, 1969) and (g) an analysis pointing out that the displacement of drugs from plasma proteins would have only a trivial effect on the plasma concentration of unbound drug, when the binding was less than $90 \%$ (Gillette, 1968). Also, in 1969, Metzler introduced the nonlinear digital computer program called NONLIN, which subsequently became very widely used (Metzler, 1969).

It is simplistic to interpret apparently multiexponential concentration-time curves on the basis of linear compartment models. Plasma protein binding and/or tissue binding of drugs are often nonlinear processes. During 1971, several authors discussed the implications of such nonlinear binding and some developed useful models (Gillette, 1971; Coffey et al., 1971; DiSanto, 1971; Wagner, 1971). During the same year, Smolen published a series of articles on assessment of drug absorption using pharmacological data (Smolen and Schoenwald, 1971; Smolen, 1971).

Suzuki et al. (Suzuki et al., 1970a,b) and Ho and Higuchi (Ho and Higuchi, 1971) discussed multicompartment diffusional models for the absorption of neutral, acidic, basic and and amphoteric drugs and applied the theory to the buccal absorption of $n$-alkanoic acids. These were the first in a long series of articles employing these models. At the end of this period, namely 1972, Benet published the first general treatment of linear mammillary models (Benet, 1972). This was followed later by general treatments by other authors (Vaughan and Trainer, 1975; Pedersen, 1978).

\section{THE SECOND GROWTH PERIOD, 1973-1979}

\subsection{Literature}

During this period pharmacokinetic literature grew at a very rapid rate. By the end of 1972 there were several journals which published pharmacokinetic articles. Examples of these are: Journal of Pharmaceutical Sciences; European Journal of Clinical Pharmacology (from Vol. 3, No. 1, December 1970 to date; formerly Pharmacologia Clinica); International Journal of Clinical Pharmacology and Biopharmacy (formerly International Journal of Clinical Pharmacology, Therapy and Toxicology); Clinical Pharmacology and Therapeutics; and Journal of Clinical Pharmacology.

During 1973-1979 these journals continued to publish their share of pharmacokinetic articles, and, in some cases, the number increased each year. For example, in Clinical Pharmacology and Therapeutics, the numbers of articles published, which dealt with aspects of pharmacokinetics, were 43 in 1973, 63 in 1974, 88 in 1975 and over 100 in 1976.

However, many of those publishing articles in the pharmacokinetic area desired their own forum, hence speciality journals were established. The three most important of these 
are: Journal of Pharmacokinetics and Biopharmaceutics, Vol. 1, No. 1, published in February, 1973; Clinical Pharmacokinetics, Vol. 1, No. 1, published in January, 1976; and Biopharmaceutics and Drug Disposition, Vol. 1, No. 1, published in July-September, 1979. Some other journals established during the same years, namely European Journal of Drug Metabolism and Pharmacokinetics, International Journal of Pharmaceutics and Therapeutic Drug Monitoring, also published many articles in pharmacokinetics.

Clinical Pharmacokinetics contains, in addition to mainly review articles and some original articles, a list of Current References in Clinical Pharmacokinetics. This section contained 465, 503 and 448 references for the years 1976, 1977 and 1978, respectively. During this period many books were published (Table 3 ).

\subsection{MODELS}

Models for elimination by the intact liver. As far back as 1963, Tait, in a review on the use of isotopically labelled steroids, stated: 'the metabolic clearance rate can be considered to be the blood flow through a hypothetic organ which completely and exclusively extracts the steroid' (Tait, 1963). He also gave examples where hepatic clearances of hormones were decreased both by change from the recumbent to the upright body position and by disease states, such as cirrhosis and congestive heart failure.

Two types of well-defined quantitative models have been developed which attempt to describe the elimination of substrates from the intact liver. One of these models has been called the well-stirred model (Pang and Rowland, 1977a,b,c) or the venous equilibration model (Bass, 1979). It was primarily developed by Rowland (Rowland et al., 1973) but many others have made significant contributions (Gibaldi and Feldman, 1969; Gibaldi et al., 1971; Perrier and Gibaldi, 1972; Perrier et al., 1973a; Evans et al., 1973; Shand et al., 1973, 1975 and 1976; Branch et al., 1973; Branch and Shand, 1976; Wilkinson, 1975; Wilkinson and Shand, 1975; Wilkinson and Schenker, 1976, Pang and Rowland, 1977a,b,c; McLean et al., 1978; Kornhauser et al., 1978). The other model has been called the parallel tube model (Pang and Rowland, 1977a) as well as the sinusoidal perfusion model (Bass, 1979). In quantitative terms this model has been stated most clearly by Bass et al. (Bass et al., 1976; 1977; 1978; Bracken and Bass, 1979), but several others have been involved in its evolution (Goresky and Bach, 1970; Winkler et al., 1973; Goresky et al., 1973; Winkler et al., 1974; Keiding et al., 1976; Keiding, 1976; Keiding and Chiarantini,

TABLE 3. Books Dealing with Pharmacokinetic Principles Published between 1973-1979

Drug Dosage Form Design and Bioavailability (Swarbrick. 1973)

Pharmacokinetik (Gladtke and von Huttingberg, 1973)

Clinical Pharmacokinetics, A Symposium (Levy, 1974a)

Basics of Bioavailability and Description of Upjohn Single Dose Study Design (Chodos and DiSanto, 1974)

Anesthetic Uptake and Action (Eger, 1974)

Manual de Iniciacion a la Biofarmacia (Farmacocinetica Aplicado) (Plá Delfina and Pozo Ojeda, 1974)

Pharmacology and Pharmacokinetics (Teorell et al., 1974)

Fundamentals of Clinical Pharmacokinetics (Wagner, 1975a)

Drug Disposition and Pharmacokinetics with a Consideration of Pharmacological and Clinical Relationships (Curry, 1974)

Biopharmaceutics and Pharmacokinetics. An Introduction, Second Edition (Notari, 1975)

Pharmacokinetics (Gibaldi and Perrier, 1975)

The Effect of Disease States on Drug Pharmacokinetics (Benet, 1976)

Pharmacokinetics of Psychoactive Drugs: Blood Levels and Clinical Response (Gottschalk and Merlis. 1976) Biopharmaceutics and Clinical Pharmacokinetics (Gibaldi, 1977)

Industrial Bioavailability and Pharmacokinetics Guidelines, Regulations, and Controls (Martin and Doluisio. 1977)

Drug Disposition and Pharmacokinetics, Second Edition (Curry, 1977)

Clinical Pharmacokinetics: Proceedings of an International Symposium at Salzgitter-Ringelheim (Ritschel. 1977)

Pharmacokinetics (Schöfeld, 1978)

Pharmacokinetics, An Introduction (Gladtke, 1979)

Textbook of Biopharmaceutics and Clinical Pharmacokinetics (Niazi, 1979)

Drug Disposition in Humans. The Basis of Clinical Pharmacology (Creasey, 1979) 
1978; Bass and Robinson, 1979). This last model has both a primitive undistributed form as well as a distributed form (Bass, 1979). The well-stirred model describes the liver as a well-stirred compartment with the drug in the hepatic venous blood being in equilibrium with that in the liver. The parallel tube model regards the liver as a series of parallel tubes with enzymes distributed evenly around the tubes and the concentration of drug declines along the length of each tube. One article of Bass gets to the crux of the difference between the two theories (Bass, 1979). There are experimental data supporting both models, and some experimental data that are not adequately explained by either theory (Pang and Gillette, 1978). The analogy between the perfusion-limited isolated organ system and the two-compartment open model with elimination from the peripheral compartment provided a physiological basis for classical pharmacokinetic compartment models (Rowland et al., 1973). The articles cited in this section also clarify that the determinants of hepatic clearance are liver blood flow, the activity of drug metabolizing enzymes and the binding of drug in blood to serum proteins and cellular elements.

From the experimental findings and theoretical considerations, a number of very useful equations were derived which relate such variables as total area under the blood concentration-time curve (AUC), the intravenous dose $(D)$ or oral dose $\left(D_{\mathrm{po}}\right)$, clearance of drug $(C L)$, availability $(F)$, extraction ratio $(E)$ and effective liver blood flow $(Q)$. For a drug which is exclusively eliminated by liver metabolism and completely absorbed, a novel way to write one of these relationships is shown as Eqns (6) and (7) where $C L_{H}$ is the hepatic clearance, $C L_{H} / F$ is the intrinsic hepatic clearance, $F=1-E$ and $V_{\max , i}$ and $K_{m, i}$ are the maximum velocities and Michaelis constants for the various

$$
\begin{aligned}
C L_{H} & =\frac{1}{\frac{1}{Q}+\frac{1}{\left(C L_{H} / F\right)}} \\
\frac{C L_{H}}{F} & =\sum_{i=1}^{n} \frac{V_{\max , i}}{K_{m, i}}
\end{aligned}
$$

biotransformation reactions occurring in the liver. One can see from Eqn (6) that when intrinsic hepatic clearance is small relative to blood flow then

$$
\frac{1}{C L_{H} / F} \gg \frac{1}{Q}
$$

and hepatic drug clearance is controlled by the metabolism reaction(s) and is essentially independent of liver blood flow. Conversely, when intrinsic hepatic clearance is large relative to blood flow, then hepatic drug clearance approaches hepatic blood flow. When intrinsic hepatic clearance is usually assigned a new symbol such as $C L_{\text {int }}$ rather than writing it as $C L_{H} / F$ or $C L_{H} /(1-E)$; this can get one into trouble since one might not realize when the variable $C L_{H}$ is separated or not.

General treatment of linear mammillary models. As indicated above, Benet published methods to obtain the integrated expressions for the amount of drug in the central (compartment no. 1) or in any peripheral compartment of an $n$-compartment mammillary model, where elimination could occur from any one or more compartments, but where input was always into the central compartment only (Benet, 1972b). Vaughan and Trainor later derived a general disposition equation for a linear mammillary model with $n$-compartments, and used it to define disposition equations for the central compartment when drug input takes place into the central or into a peripheral compartment. Equations describing the entire time-course of drug in a particular compartment after intravenous, intramuscular, oral and rectal drug administration were presented (Vaughan and Trainor, 1975). Pederson later published another general treatment for input into one or more compartments and elimination from one or more compartments. Two approaches were described: one based on a full Laplace transformation and one that avoids trans- 
formation of the input function(s) and the use of convolution integrals. The latter approach is important when dealing with complex input functions not having a simple Laplace transform (Pederson, 1978).

Cancer chemotherapy models. Jusko proposed a pharmacodynamic model for the quantitative analysis of dose-time-cell survival curves produced by the administration of cell-cycle-specific chemotherapeutic agents (Jusko, 1973). Himmelstein and Bischoff developed predictive models to simulate cancer cell populations under treatment with cytotoxic drugs, with both direct-acting and cell-cycle-specific drugs. Models of cell growth kinetics were combined with simple pharmacokinetic models to complete the cell-drug interaction system (Himmelstein and Bischoff, 1973a). These models were applied to the treatment of L1210 leukemia in mice with ARA-C (1- $\beta$-D-arabinofuranosylcytosine) and the results of various treatment schedules were simulated; the simulated data agreed quite well with experimental data (Himmelstein and Bischoff, 1973b). Physiologically-based pharmacokinetic models for anticancer drugs were reviewed by Chen and Gross (Chen and Gross, 1979a).

Other physiologically-based pharmacokinetic models. The physiological pharmacokinetic approach to the modeling of drug distribution was reviewed (Himmelstein and Lutz, 1979). One advantage of such modeling is that it allows extrapolation outside the range of data, with some confidence, if the dominant mechanisms of transport are sufficiently well understood. Another advantage is that one may scale from a species of one size to that of a larger or smaller size. The compartments of such models correspond to anatomical spaces so that biochemical interactions, including drug effects or pharmacodynamics, may be incorporated in the model.

Two experimental methods are important with respect to these models. Rane et al. described a method to predict intrinsic clearance for an in vivo model from enzyme kinetic data obtained in vitro. They reported a remarkably good correlation between hepatic clearance predicted by the method and the clearance observed in isolated liver preparations. The method, in effect, utilizes Eqn (7) above (Rane et al., 1977). Important parameters in the development of physiologically-based models are the tissue-to-plasma partition coefficients. The estimation of these parameters have been discussed in detail (Chen and Gross, 1979b).

Stochastic models. Several articles dealing with stochastic theory of one- and twocompartment systems (Purdue, 1974), as well as the solution for an n-compartment system with irreversible time-dependent transition probabilities (Cardenas and Matis, 1974), have appeared. In addition, a general time-independent stochastic model was described (Faddy, 1976). Vaughan and Hope discussed applications and advantages of a recirculatory stochastic pharmacokinetic model for representing drug distribution and elimination (Vaughan and Hope, 1979).

Linear plasma protein and tissue binding. Levy and Yacobi showed that the total plasma clearance of the highly plasma protein bound drug, warfarin, in rats was a linear function of the free (unbound) fraction of drug in plasma (Levy and Yacobi, 1974b; Yacobi and Levy, 1975 and 1977).

Gillette has published articles which illustrate the importance of linear plasma protein and tissue binding in drug disposition (Gillette, 1971 and 1973; Gillette and Pang, 1977) and the literature on such binding has been well reviewed (Wagner, 1973b; Jusko and Gretch, 1976). Simple pharmacokinetic models incorporating linear plasma protein binding, linear tissue binding and first-order elimination of free (unbound) drug were studied intensively (Wagner, 1976b; Gibaldi and McNamara, 1978).

Based on an equation of Gillette (Gillette, 1971), Wilkinson and Shand proposed that Eqn (8) would apply, where $V$ is the apparent volume of distribution of a drug with respect to the total systemic venous drug concentration, $V_{B}$ represents the blood volume, $V_{T}$ represents the volume of

$$
V=V_{B}+V_{T}\left(\frac{f u_{b}}{f u_{T}}\right)
$$


other tissues of the body into which the drug distributes and $f u_{T}$ and $f u_{b}$ are the fractions of drug present in the unbound form in the tissue and blood, respectively (Wilkinson and Shand, 1975). Gibaldi and McNamara showed a derivation of an equation with the same form as Eqn (8), but the symbols were defined as follows: $V_{B}$ is the plasma volume, $V_{T}$ is the difference between the volumes of total body water and plasma, and $f u_{T}$ is the fraction of drug unbound in tissue (i.e. the weighted average fraction of free drug in extraplasma space) and $V$ is the steady-state volume of distribution (Gibaldi and McNamara, 1978). This is a considerably different interpretation of the equation. The latter equation was then used to derive some other relationships concerning the effect of plasma protein and tissue binding on the biologic half-life of drugs (Gibaldi et al., 1978). However, Øie and Tozer pointed out that the interpretation of Gibaldi and McNamara did not take into account that plasma proteins are also distributed throughout the extracellular fluids. They derived a much more complicated expression for the volume of distribution of a drug (Øie and Tozer, 1979).

Nonlinear pharmacokinetics and models. Evidence of nonlinearities in pharmacokinetic data goes back to the early 1930's, with the origination of the concept that ethyl alcohol is sometimes eliminated at a fixed rate, independent of its concentration in the body. The author's review article (Wagner, 1973b), contained references to over 160 articles which suggest evidence of nonlinearities in drug absorption, distribution, metabolism and excretion and the pharmacokinetics of drug action. A later review also presented extensive evidence of nonlinearities (Jusko and Gretch, 1976). Nonlinear elimination kinetics will be considered first, followed by nonlinear plasma protein and tissue binding.

By means of theoretical considerations and simulations it was shown that an apparent increase in the biological half-life of a drug with increasing dose could result from product inhibition if the dissociation constant for the drug metabolite-enzyme complex is appreciably lower than the Michaelis constant for the drug-enzyme complex, if drug metabolite concentrations remain relatively constant for some time as a result of slow elimination of the metabolite, and if the level of drug in the body does not appreciably exceed the apparent in vivo Michaelis constant (Perrier et al., 1973b). A theory which explains phenomena exhibited by pooled nonlinear pharmacokinetic systems and equations relating pooled Michaelis-Menten constants $V m_{p}, K m_{p}$, to microscopic constants $V m_{i}, K m_{i}$ was presented (Sedman and Wagner, 1974). A model, based on physiologic considerations, was shown to describe the entire time course of blood alcohol concentrations after four different doses of alcohol administered orally (Wilkinson et al., 1977). If elimination obeys Michaelis-Menten kinetics, the rate of accumulation depends not only on the magnitudes of the maximal velocity and Michaelis constant but also on the rate of drug input to the body. Simulations of the time course of drug accumulation were carried out for phenytoin--a drug whose elimination obeys Michaelis-Menten kinetics (Wagner, 1978; Ludden et al., 1978; Lam and Chiou, 1979). These theoretical predictions were supported by the measurement of phenytoin serum concentrations (Allen et al., 1979).

Kunka and Mattocks showed that one of the nonlinear models of DiSanto (1971) and Wagner (1971b) adequately described the pharmacokinetics of acetazolamide in the rabbit (Kunka and Mattocks, 1979). The model employed involved two saturable tissue binding sites and first-order elimination of free (unbound) drug. Extraction of propranolol by the perfused rat liver was shown to be dose-dependent (Evans et al., 1973). This article, by Evans et al., is unique in that it is the only work with physiologically-based modeling in which the parameters were simultaneously and statistically best fitted to the data. The pharmacokinetic analysis provided new insight into the biology of the system which was not apparent from the raw data, or from any simple manipulation thereof. The clinical importance of the nonlinear plasma protein binding of disopyramide was emphasized. In the 12 patients studied, at any given total disopyramide plasma concentration, there was approximately a twofold range in the fraction of disopyramide unbound to plasma proteins. Hence mean plasma protein binding data or data on protein binding obtained from pooled plasma are of little value in a given patient, for 
predicting unbound disopyramide concentrations from measurements of total disopyramide concentrations (Meffin et al., 1979).

Simulation of plasma drug concentration-time profiles for a number of systems incorporating nonlinear plasma protein and/or tissue binding were reported. For the extensive conclusions the original articles should be consulted (McNamara et al., 1979a,b). One of the conclusions of this work was that for nonlinear plasma protein and/or tissue binding models there will always be a pronounced ' $\alpha$-' or 'distribution' phase after cessation of an infusion for any length of time, whereas in a linear pharmacokinetic system the ' $\alpha$-' or 'distribution' phase tends to disappear the longer is the infusion time. However, in linear systems it is not only the infusion time but also the value of the ratio $C_{2} \lambda_{1} / C_{1} \lambda_{2}$ which determines the degree of disappearance of the $\alpha$-phase (Kampman, 1979); here $C_{1}$ and $\lambda_{1}$ are the coefficient and the exponential coefficient respectively, of the first term and $C_{2}$ and $\lambda_{2}$ are the coefficient and exponential coefficient of the second term of the biexponential equation for a linear system after bolus intravenous administration.

How the area-dose and area-initial plasma concentration relationships may be used to study nonlinear processes was explored and a general theorem proven. Assuming Michaelis-Menten elimination kinetics and Langmuir type tissue binding, several areadose and area-initial plasma concentration relationships were derived (Chau, 1976).

Miscellaneous. Pharmacokinetic models and the basic concepts involved in applying models to blood, urine, bile and tissue levels of drugs and metabolites were reviewed (Garrett, 1973). The principle of area analysis was used in the development of a metabolic and pharmacokinetic model for an extensively biotransformed drug, $\mathrm{N}_{\mathbf{4}}$-ethoxyacetylsulfamethoxazole in the monkey (Kaplan et al., 1973). The first attempt to define quantitatively by radioautography the rate and extent of metabolism of a cephalosporin antibiotic in animals and man was made by Cabana et al. They also established, by renal and metabolic clearance measurements, the definite role of the kidney in drug metabolism. Their studies demonstrated that the renal clearance of desacetylcephapirin, an active metabolite of cephapirin, was not proportional to its plasma concentration and that the clearance far exceeded renal plasma flow (Cabana et al., 1975). Niazi defined a volume of distribution as a function of time for a multicompartment model; it equals the usual value, based on area considerations, in the log-linear phase of plasma concentration-time data (Niazi, 1976). A linear recirculation model for drug disposition in which disposition is regarded as the result of repetitive passes of the drug around the circulation was described (Cutler, 1979). A new definition of a compartment in pharmacokinetic modeling was published (Cutler, 1978a).

\subsection{Model-INdePENDENT Methods}

The convolution integral of Stephenson (Stephenson, 1960) is useful in linear systems analysis (Cutler, 1978b). Numerical deconvolution methods were described and illustrated by several authors (Rescigno and Segré, 1966; Benet and Chiang, 1972a; Wagner, 1975b; Cutler, 1978c,d).

Dost's law of corresponding areas was stated as: 'the ratio of the area beneath the blood level-time curves, after oral administration to that following intravenous administration of the same dose, is a measure of the absorption of the drug administered' (Dost, 1968). When 'absorption' is equated with 'efficiency of absorption' both Nüesch (Nüesch, 1973) and Vaughan (Vaughan, 1977) offered proofs of Dost's law. However, a drug may be completely absorbed but only a fraction of the dose reach the circulation intact as a result of the 'first pass' effect. Hence, Wagner suggested that Dost's law of corresponding areas be replaced by Eqn (9), where $F$ is the fraction of the dose, $D_{p 0}$, which is absorbed $(0 \leq F \leq 1), F^{*}$ is the bioavailability

$$
F F^{*}=\frac{\left[\int_{0}^{\infty} C \mathrm{~d} t\right]_{p 0}}{\left[\int_{0}^{\infty} C \mathrm{~d} t\right]} \cdot \frac{D}{D_{p 0}}
$$


factor due to the first-pass effect $\left(0 \leq F^{*} \leq 1\right), D$ and $D_{p 0}$ are the intravenous and oral doses, respectively, and the integrals are the total areas under the concentration-time curves following oral and intravenous administration, respectively. He also showed that for some models $F^{*}=1$ and for others $F^{*} \neq 1$ (Wagner, 1976c). In the real world we also know that drugs with high hepatic clearances have a significant liver 'first-pass' effect and that other drugs are metabolized as they pass through the gut wall, which also would make $F^{*}$ less than unity. Dost also extended his method to obtain an absorption profile of the drug via a graphical procedure, which was shown by Galeazzi and Benet to be the graphical equivalent of the Wagner-Nelson method (Galeazzi and Benet, 1976; Wagner and Nelson, 1963). Still later Dost (Dost, 1970a,b) extended his graphical procedure to multicompartment systems, but this was shown to be inappropriate (Galeazzi and Benet, 1976).

Some model-independent prediction methods for use in pharmacokinetics were discussed by Amidon et al. (Amidon et al., 1975). One of these was a method to estimate the asymptote of a curve when the values of the function are approaching the asymptote according to first-order kinetics (monoexponential function). Their method employed three concentration-time points and was extended to any number of points (Wagner and Ayres, 1977). These methods are most useful for estimating the area under a concentration-time curve from zero to infinite time or the cumulative amount of a drug excreted in the urine in infinite time after a single dose of drug. The method was later extended to biexponential processes (Newburger et al., 1979).

An important parameter in pharmacokinetics is the volume of distribution steady state, which has had an interesting history. If the kinetics are linear then the time course of the plasma drug concentration, $C$, following a single i.v. bolus dose will be given by Eqn (10). The volume of distribution steady state, $V_{\mathrm{ss}}$, is then given by Eqn (11),

$$
C=\sum_{i=1}^{n} C_{i} \mathrm{e}^{-i_{i} ;}
$$

where $A_{\text {eq }}$ and $C_{\text {eq }}$ are respectively the amount of drug in the body and the plasma drug concentration at equilibrium (i.e. the instant in time when the rate of change of drug in the one or more peripheral compartments of the $n$-compartment mammillary model is equal to zero), $k_{12}, k_{21}, \ldots k_{l n}, k_{n l}$ are the forward

$$
V_{\mathrm{ss}}=\frac{A_{\mathrm{eq}}}{C_{\mathrm{eq}}}=\left[1+\frac{k_{12}}{k_{21}}+\cdots+\frac{k_{i n}}{k_{n l}}\right] V_{1}=\frac{\bar{A}_{\mathrm{ss}}}{\bar{C}_{\mathrm{ss}}}=\frac{D \sum_{i=1}^{n} C_{i} / \hat{\lambda}_{i}^{2}}{\left[\sum_{i=1}^{n} C_{i} / \lambda_{i}\right]^{2}}=\frac{D \int_{0}^{\infty} t C \mathrm{~d} t}{\left[\int_{0}^{\infty} C \mathrm{~d} t\right]^{2}}=\bar{t} C L
$$

and reverse first-order rate constants between the peripheral compartments and the central compartment, $V_{1}$ is the volume of the central compartment, $\bar{A}_{\mathrm{ss}}$ and $\bar{C}_{\mathrm{ss}}$ are the average amount of drug and concentration, respectively, at steady state in the $n$-compartment mammillary model with elimination from the central compartment only, $D$ is the dose after bolus intravenous injection, $\bar{t}$ is the mean residence time [see Eqn (2)] and $C L$ is the mean drug clearance. Riggs first defined $V_{\text {ss }}$ for the two-compartment open mammillary model with elimination from the central compartment only (i.e. $n=2)$, using the second and third equalities of Eqn (11) (Riggs, 1963). $V_{s s}$ and other 'volumes of distribution' were discussed later (Riegelman et al., 1968b). A volume of distribution was defined by the equivalent of the fifth equality of Eqn (1) in a footnote of a table in a chapter by van Rossum (van Rossum, 1971). The derivation of the fifth equality of Eqn (11), based or. the fourth equality was given by Wagner (Wagner, 1976d). Oppenheimer et al. (Oppenheimer et al., 1975) defined a noncompartmental volume of distribution with the sixth and seventh equalities of Eqn (11). Benet and Galeazzi clarified that this noncompartmental volume of distribution was equivalent to the $V_{\mathrm{ss}}$ which had been used for many years, and that the integrals in the sixth equality of Eqn (11) could be estimated 
directly from $C, t$ data without use of a model at all (Benet and Galeazzi, 1979). Hence a volume that was originally defined very restrictively has evolved into a model-independent term.

\subsection{Optimal Input Calculations}

A safe method for rapidly achieving plasma concentration plateaus (i.e. steady-state concentrations) based on the two-compartment open model and involving two consecutive infusion rates was reported (Wagner, 1974). Later a general derivation was made and applied to steady-state concentrations of lignocaine (Vaughan and Tucker, 1976). In addition, a general method was described for computing drug regimens which are optimal in the sense of minimizing the sum of squared deviations of the predicted drug concentration in a compartment from a desired concentration in that compartment (Wheeler and Sheiner, 1976).

\subsection{COMputers and Statistical ANalysis}

Several important statistical aspects of pharmacokinetic analysis were discussed (Boxenbaum et al., 1974). These included selection of appropriate equations, weighting of data, precision of parameter estimates, analysis of weighted residuals, and criteria useful in selection of the final model. Colburn et al. published a digital computer program which utilizes the nonlinear least squares regression program NONLIN (Metzler, 1969) to fit particular models to concentration-time data when the data are collected during repetitive dosing of the drug (Colburn et al., 1976). Sheiner et al. described a method of estimating population characteristics of pharmacokinetic parameters from routine clinical data (Sheiner et al., 1977). Several drug concentration values from each individual, along with dosage information and the results of other routinely assessed variables suffice for purposes of analysis. The generality and appropriateness of the analytic technique were demonstrated by analysis of a set of data derived from 141 patients who were receiving digoxin. The usefulness of statistical moments of concentration-time data was emphasized (Yamaoka et al., 1978). A digital computer study using simulated data with random error indicated no difference in the precision and accuracy of parameter estimation when several different equations were fitted to the data, each set of which related to the same model (Wong et al., 1979).

In 1974, AUTOAN, a decision-making pharmacokinetic program, was made available, and subsequently described (Wagner, 1975a). This program is really a large so-called DFUNC subroutine of the digital computer program NONLIN (Metzler, 1969).

\subsection{Bioavailability}

Factors affecting the magnitude of the 'first pass' effect were discussed in detail (Riegelman and Rowland, 1973; Benet, 1978) and the effect of the route of administration and the distribution of the drug on drug action were reviewed (Benet, 1978). A method was proposed for estimating the bioavailability of a drug whose elimination from a onecompartment body model occurs by one or more apparent first-order processes in parallel with one capacity-limited or Michaelis-Menten pathway (Martis and Levy, 1973). Some new methods of estimating drug bioavailability under single dose and quasiand nonsteady-state conditions were described in detail (Kwan and Till, 1973; Till et al., 1974, Kwan et al., 1975). The use of data derived from the monitoring of the time variation of the intensity of a pharmacological response or effect following dosing has been championed by Smolen; such data can be utilized in bioavailability assessment (Smolen and Wiegand, 1973; Smolen, 1976a,b). An excellent example of how to differentiate between liver and gastrointestinal 'first pass' metabolism was reported (Cotler et al., 1976). Albert et al. (Albert et al., 1979) showed that within-lot and between-lot uniformities in bioavailability of methylprednisolone from commercial tablets are very similar, 
suggesting that the observed variability in serum methylprednisolone concentrations was not the result of manufacturing variables. Some important aspects of estimating bioavailability of digoxin were discussed and illustrated (Wagner and Ayres, 1977).

\subsection{DRUG INTERACTIONS}

Rowland and Matin pointed out that since many drug-drug pharmacokinetic interactions are dependent on the concentrations of the interacting species, the degree of interaction should be a graded phenomenon varying with the drug and/or metabolite concentration and thus drug administration and time. They discussed the interaction of phenobarbital with griseofulvin, sulfaphenazole with tolbutamide, and warfarin with phenylbutazone and stressed the importance of measuring not only intact drug administered but also metabolites in drug interaction studies (Rowland and Matin, 1973). Levy reviewed some pharmacokinetic approaches to the study of drug interactions (Levy, 1976). A steady-state blood concentration method for detecting and quantitating drugdrug interactions was illustrated by the ethanol-propranolol interaction in the cat (Wagner et al., 1976b). Gillette and Pang used a blood flow rate-limited (physiologicallybased) type of model to indicate the possible effects of drug interactions on measurable variables (Gillette and Pang, 1977).

\subsection{Clinical Pharmacokinetics}

As indicated in a previous section of this chapter the number of published articles specifically in the clinical pharmacokinetics area had reached at least a rate of $400-500$ articles per year by 1979. In writing this section no attempt has been made to review and/or evaluate this large body of literature or to choose what the author considers to be the most important articles, as was done in most of the other sections of this chapter. Rather, the few articles discussed below are merely examples of the literature.

One type of clinical pharmacokinetic article may be classified as educational, where the purpose is to acquaint those unfamiliar with pharmacokinetics with the terminology and examples. This type is exemplified by the articles of Gibaldi and Levy entitled Pharmacokinetics in Clinical Practice, which were published in the Journal of the American Medical Association (Gibaldi and Levy, 1976a,b), and by the article of Dettli, in which he discussed examples of pharmacokinetic analyses which influence the practice of therapeutics (Dettli, 1973).

Another type of article consists of a compilation and quick reference. An example here is the article of Pagliaro and Benet who critically compiled values of terminal half-lives, percent drug excreted unchanged in urine, and changes of half-life in patients with renal and hepatic dysfunction (Pagliaro and Benet, 1975).

A third type of article is one directed at describing pharmacokinetic monitoring of a drug during therapy. The specialty of clinical pharmacokinetics encompasses the rational employment of theoretical pharmacokinetics to evolve practical guidelines for drug therapy in patients, with subsequent assessment of the utility and appropriateness of such guidelines by monitoring serum concentrations. The article of Koup et al. describing a system for guiding and monitoring theophylline therapy serves as an example in this area (Koup et al., 1976).

A fourth type of article is the review, frequently bearing a title such as 'The Clinical Pharmacokinetics of Drug $X$ '. The issues of the journal Clinical Pharmacokinetics have carried many such reviews and these now are too numerous to be listed.

The fifth type of article is the 'original literature' type where new experimental data are presented. An example here is the article by Klotz et al. who reported on the effect of age and liver disease on the disposition and elimination of diazepam in adult men (Klotz et al., 1974). The prolongation of the apparent elimination half-life of diazepam was shown to be caused by two different mechanisms: (1) in liver disease metabolic clearance is decreased; (2) in aging the volume of distribution of the drug is increased. The authors 
also explored the role of altered disposition in the frequency of side effects resulting from administration of diazepam.

Pharmacokinetics should not be viewed in isolation, but rather as a tool to improve rational drug therapy. The rapid growth of pharmacokinetics during the past two decades has been made possible largely by vast improvements in analytical methodology. Listed below are ideas (see Acknowledgement) on the possible future use of pharmacokinetics in patient care. Some of these are being performed at the time of writing, but perhaps their use will become more widespread in the future.

Future use of pharmacokinetics for patient care include:

(1) Individualization of patient dose and dosage regimen.

(2) Use of pharmacokinetic parameters as variables to guide rational synthesis and testing of new chemotherapeutic agents.

(3) Development and use of non-invasive methods of assessing drug concentrations in patients.

(4) Characterization and prediction of the time course of the intensity of pharmacologic effects.

(5) Continuation and improvement in the use of pharmacokinetics in the assessment of the bioavailability of a drug, from different dosage forms and the same dosage form made by two or more manufacturers, or given by different routes.

(6) More emphasis on a comparison of intra- and inter-subject variabilities in pharmacokinetic parameters.

(7) Possible development of a 'sub-therapeutic cocktail' of various compounds, followed by routine analysis of biological samples taken from the patient, to obtain profiles of the compounds which would reflect the magnitudes of pharmacokinetic parameters which, in turn, would be useful in guiding therapy in the drugs.

(8) Aid in determining the mechanism of drug-drug interactions and their avoidance.

(9) Use of pharmacokinetic principles to guide in the use of some drugs in some patients.

(10) Development of pharmacokinetic laboratories and/or centers throughout the world to guide physicians in their use of drugs.

(11) Prediction of pharmacokinetics of drugs in man from results obtained in animals, using physiologically-based models and scale-up factors.

(12) Use of pharmacokinetics as a diagnostic tool, such as in acetylation testing.

(13) Improvement in the quality and specificity of drug use in patients.

(14) Identification of optimum methods to accelerate drug elimination from the body in cases of toxicity and/or overdosage.

(15) Identification of active metabolites of drugs and quantitation of their role in producing the overall response following drug administration.

(16) Development and use of sophisticated digital computer programs to obtain population estimates of pharmacokinetic parameters and their variabilities, which, in turn, would aid in drug therapy of other patients.

(17) Education of physicians and other health professionals concerning what pharmacokinetics can do in improving the rational use of drugs.

Acknowledgements - In the Fall of 1976 the author sent a questionnaire regarding the history of pharmacokinetics to several scientists who have published pharmacokinetic articles. The author gratefully acknowledges the answers to the questionnaire received from Drs. B. E. Cabana, E. R. Garrett, M. Gibaldi, J. R. Gillette, G. Levy, W. J. Jusko, S. A. Kaplan, M. Rowland, T. Teorell, E. S. Vessell and G. R. Wilkinson. Some evaluations of their own contributions are used in the manuscript as well as some of their ideas concerning the future use of pharmacokinetics in patient care.

\section{REFERENCES}

Albert, K. S., Brown, S. W., JR., DeSante, K. A., DiSanto, A. R., Stewart, R. D. and Chen. T. T. (1979) Double latin square study to determine variability and relative bioavailability of methylprednisolone. $J$. Pharm. Sci. 68: 1312-1316. 
Allen, J. P., Ludden, T. M., Burrow, S. R., Clementi, W. A. and Stavchansky, S. A. (1979) Phenytoin cumulation kinetics. Clin. Pharmac. Ther. 26: 445- 448.

Amidon, G. L., Paul, M. J. and Welling, P. G. (1975) Model-independent prediction methods in pharmacokinetics: Theoretical considerations. Mathl. Bio. Sci. 25: 259-272.

AtKINS, G. L. (1969) Multicompartment Models for Biological Systems, Methuen, England.

Bass, L., Keiding, S., WinkLer, K. and TygstruP, N. (1976) Enzymatic elimination of substrates flowing through the intact liver, J. Theor. Biol. $61: 393-409$.

Bass, L. and BRACKEN, A. J. (1977) Time-dependent elimination of substrates flowing through the liver or kidney. J. Theor. Biol. 67: 637-652.

Bass, L., Robinson, P. and Bracken, A. J. (1978) Hepatic elimination of flowing substrates: The distributed model. J. Theor. Biol. 72: 161-184.

Bass, L. (1979) Current models of hepatic elimination. Gastroenteroloay 76: 1504-1505.

BASs, L. and Robinson, P. (1979) How small is the functional variability of liver sinusoids? Applied Mathematics reprint No. 110. Dept. of Mathematics, University of Queensland, Brisbane, Australia.

Beckett, A. H. and Rowland, M. (1965) Urinary excretion kinetics of amphetamine in man. J. Pharm. Pharmac. 17: 628-639.

Benet, L. Z. and Chiang, C.-W. N. (1972a) The use of deconvolution methods in pharmacokinetics. In Abstracts of Papers Presented at the 13th National Meeting of the APhA Academy of Pharmaceutical Sciences, Chicago, November 5-9, 1972, Vol. 2, No. 2, pp. 169-171.

BENET, L. Z. (1972b) General treatment of linear mammillary models with elimination from any compartment as used in pharmacokinetics. J. Pharm. Sci. 61: 536-540.

Bent, L. Z. (ed) (1976) The Effect of Disease States on Drug Pharmacokinetics. Academy of Pharmaceutical Sciences, American Pharmaceutical Association, Washington, D.C.

BENT, L. Z. (1978) Effect of route of administration and distribution on drug action. J. Pharmacok. Biopharm. 6 $559-585$.

Benet, L. Z. and Galeazzi, R. L. (1979) Noncompartmental determination of the steady-state volume of distribution. J. Pharm. Sci. 68: 1071-1074.

Berman, M. and SCHOENFELD, R. (1956) Invariants in experimental data in linear kinetics and the formation of models. J. appl. Physiol. 27: 1361-1370.

Berman, M. and Weiss, M. F. (1966) SAAM Manual, Public Health Service Manual No. 1703, U.S. Government Printing Office, Washington, D.C.

Bischoff, K. B. and Dedrick, R. L. (1968) Thiopental pharmacokinetics. J. Pharm. Sci 57: 1347-1357.

Bischoff, K. B., Dedrick, R. L., Zaharko, D. S. and Longstreth. J. A. (1971) Methotrexate pharmacokinetics. J. Pharm. Sci. 60: 1128-1133.

Boxer, G. E. and Jelinek, V. C. (1948) Streptomycin in the blood: Chemical determinations after single and repeated intramuscular injections. J. Pharmac. exp. Ther. 92: 226-235.

Boxenbaum, H. G., Riegelman, S. and Elashoff, R. M. (1974) Statistical estimations in pharmacokinetics. $J$. Pharmacok. Biopharm. 2: 123-148.

Bracken, A. J. and Bass, L. (1979) Statistical mechanics of hepatic elimination. Mathl. Bio. Sci. 44: 97-120.

Branch, R. A., NiES, A. S. and Shand, D. G. (1973) The disposition of propranolol VIII. General implications of the effects of liver blood flow on elimination from the perfused rat liver. Drug Metab. Dispos. 1:687-690.

Branch, R. A. and Shand, D. G. (1976) Propranolol disposition in chronic liver disease: A physiological approach. Clin. Pharmacok. 1: 264-279.

Bray, H. G., ThORPE, W. V. and WHITE, K. (1951) Kinetic studies of the metabolism of foreign organic compounds I. The formation of benzoic acid from benzamide, toluene, benzyl alcohol and benzaldehyde and its conjugation with glycine and glucuronic acid in the rabbit. Biochem. J. 48: 88-96.

Brodie, B. B., Kurz, H. and Schanker, L. S. (1960) The importance of dissociation constant and lipid solubility in influencing the passage of drugs into the cerebrospinal fluid. J. Pharmac. exp. Ther. 130: $20-25$.

Buchanan, A. (1847) Physiologic effects of the inhalation of ether. London Med. Gaz. 39: 715-717.

Burns, J. J., ConNeY, A. H. and Koster, R. (1963) Stimulatory effect of chronic drug administration on drug-metabolizing enzymes in liver microsomes. Ann. N.Y. Acad. Sci. 104: 881-893.

Butler, T. C., Mahaffe, C. and Waddel, W. J. (1954) Phenobarbital: Studies of elimination, accumulation, tolerance and dosage schedules. J. Pharmac. exp. Ther. 111: 425-435.

ButLeR, T. C. (1958) Termination of drug action by elimination of unchanged drug. Fedn. Proc. 17: 1158-1162.

Butler, R. A. (1964) Pharmacokinetics of halothane and ether. Br. J. Anesth. 36: 193-199.

Cabana, B. E., Van Harken, D. R., Hottendorf, G. H., Doluisio, J. T., Griffen. W. O., Jr., Bourne, D. W. A. and DitTerT, L. W. (1975) The role of the kidney in the elimination of cephapirin in man. $J$. Pharmacok. Biopharm. 3: 419-438.

Cardenas, M. and Matis, J. H. (1974) On the stochastic theory of compartments: Solution for n-compartment system with irreversible time-dependent transition probabilities. Bull. Math. Biol. 36: 489-504.

Chau, N. P. (1976) Area-dose relationships in nonlinear models. J. Pharmacok. Biopharm. 4: 537-551.

Chen, H.-S. G. and Gross, J. F. (1979a) Physiologically based pharmacokinetic models for anticancer drugs. Cancer Chemother. Pharmac. 2: 85-94.

Chen, H.-S. G. and Gross, J. F. (1979b) Estimation of tissue-plasma partition coefficients used in physiological pharmacokinetic models. J. Pharmacok. Biopharm. 7: 117-125.

Chodos. D. J. and DiSanto. A. R. (1974) Basics of bioavailability and description of the Upjohn single dose study design. The Upjohn Company, Kalamazoo, MI.

Coffey, J. J., Bullock, F. J. and Schoenemann (1971) Numerical solution of nonlinear pharmacokinetic equations: Effects of plasma protein binding on drug distribution and elimination. J. Pharm. Sci. 60: $1623-1628$.

Colburn, W. A., Shen, D. and Gibaldi, M. (1976) Pharmacokinetic analysis of drug concentration data obtained during repetitive drug administration. J. Pharmacok. Biopharm. 4: 469-489. 
Cornfield, J., Steinfeld, J. and Greenhouse, S. W. (1960) Models for interpretation of experiments using tracer compounds. Biometrics 16: 212-234.

Cotler, S., Holazo, A., Boxenbaum, H. G. and Kaplan, S. A. (1976) Influence of route of administration on physiological availability of levodopa in dogs. J. Pharm. Sci. 65: 822-827.

Creasey, W. A. (1979) Drug Disposition in Humans. The Basis of Clinical Pharmacology. Oxford University Press, New York, N.Y.

Cucinell, S. A., Conney, A. H., Sansur, M. and Burns, J. J. (1965) Drug interactions in man I. Lowering effect of phenobarbital on plasma levels of bishydroxycoumarine (Dicumarol) and diphenylhydantoin (Dilantin). Clin. Pharmac. Ther. 6: 420-429.

CURry, S. (1974) Drug Disposition and Pharmacokinetics with a Consideration of Pharmacological and Clinical Relationships. Blackwell (Lippincott), Philadelphia, PA.

CURry, S. H. (1977) Drug Disposition and Pharmacokinetics (2nd ed). Blackwell Scientific, London.

CuTLER, R. E. and ORME, B. M. (1969) Correlation of serum creatinine concentration and kanamycin half-life. $J$, Am. med. Ass. 209: 539-542.

CUTLER, D. J. (1978a) On the definition of the compartment concept in pharmacokinetics. J. Theor. Biol. 73: 329-345.

CUTLER, D. J. (1978b) Linear systems analysis in pharmacokinetics. J. Pharmacok. Biopharm. 6: 265-282.

CUTLER, D. J. (1978c) Numerical deconvolution by least squares: Use of prescribed input functions. J. Pharmacok. Biopharm. 6: 227-241.

Cutler, D. J. (1978d) Numerical deconvolution by least squares: Use of polynomials to represent the input function. J. Pharmacok. Biopharm. 6: 243-263.

CutLer, D. J. (1979) A linear recirculation model for drug disposition. J. Pharmacok. Biopharm. 7: 101-116.

Dedrick, R. L. and Bischoff, K. B. (1968) Pharmacokinetics in applications of the artificial kidney. Chem. Engng. Progr. Symp. Ser. $64:$ 32-44.

DE JONG, S. E. and WIJANS, M. (1950) The influence of divided doses of drugs on the duration of effect and intergral of effect. Acta. physiol. pharmacol. néerl. 1 : 237-258.

Dettli, L., Spring, P. and Habersang, R. (1967) Drug dosage in patients with impaired renal function. Postgrad. Med. J. 46: 32-35, Suppl.

DetTLI, L. (1970) Multiple dose elimination kinetics and drug accumulation in patients with normal and with impaired kidney function. In: Adv. Biosci. 5. Schering Workshop on Pharmacokinetics, Berlin 1969, p. 39-54. Pergamon Press, New York.

DetTl, L. (1973) Translation of pharmacokinetics to clinical medicine. J. Pharmacok. Biopharm. 1: 403 418.

DiSanto, A. R. (1971) A new nonlinear pharmacokinetic model with specific application to methylene blue. Ph.D. dissertation, The University of Michigan.

Dittert, L. W., Cressman, W. A., Kaplan, S. A., Riegelman, S. and Wagner, J. G. (1972) Guidelines for Biopharmaceutical Studies in Man, Academy of Pharmaceutical Sciences, American Pharmaceutical Association, Washington, D.C., U.S.A.

Dominguez, R. and Pomerene, E. (1934) Studies of renal excretion of creatinine I. On the functional relation between the rate of output and the concentration in the plasma. J. Biol. Chem. 104: 449-471.

Dominguez, R. (1934) Studies of renal excretion of creatinine II. Volume of distribution. Proc. Soc. exp. Biol. Med. 31: $1146-1150$.

Dominguez, R., Goldblatt, H. and Pomerene, E. (1935) Kinetics of the elimination of substances injected intravenously (experiments with creatinine). Am. J. Physiol. 114:240-254.

Dominguez. R. and Pomerene, E. (1944) Kinetics of the disappearance of galactose from the plasma after a rapid intravenous injection. Am. J. Physiol. $141: 368-381$.

Dominguez, R. and Pomerene, E. (1945a) Calculation of the rate of absorption of exogenous creatinine. Proc. Soc. exp. Biol. Med. 60: 173-181.

Dominguez, R. and Pomerene, E. (1945b) Recovery of creatinine after ingestion and after intravenous injection in man. Proc. Soc. Exp. Biol. Med. 58: 26-28.

Dominguez, R., Corcoran, A. C. and Page, I. H. (1947a) Mannitol: Kinetics of distribution, excretion and utilization in human beings. J. Lab. clin. Med. 32: 1192-1202.

Dominguez, R., Goldblatt, H. and Pomerene, E. (1947b) Kinetics of the excretion and utilization of xylose. Am. J. Physiol. 119: 429-438.

Dominguez, R. (1950) Kinetics of elimination, absorption and volume of distribution in the organism. In: Medical Physics II, Yearbook Publishers, Chicago.

Dost, F. H. (1953) Der Blütspiegel-Kinetic der Konzentrationsablaüfe in der Krieslauffüssigkeit. G. Thieme, Leipzig, p. 244.

Dost, F. H. (1968) Grundlagen den Pharmacokinetik. G. Thieme, Leipzig.

Dost, F. H. (1970a) Eine Prozedur zur fortlaufenden Messung von Absorptionsquoten nach dem Prinzip der Korrespondierenden Flächen. Pharmac. Clin. 2: 173-176.

Dost, F. H. (1970b) Transfer und Transit als Pharmacokinetische Mengenbeziehungen in Einem Multicompartiment-Modell. Deutsch. med. Wschr. 95: 1713-1716.

Duncan W. A. M. and Raventós, J. (1959) The pharmacokinetics of halothane anesthesia. Br. J, Anaesth. 31 : 302-315.

Edelman, I. S. and Liebman, J. (1959) Anatomy of body water and electrolytes. Am. J. Med. 27: 256-277.

EGER, E. (1974) Anesthetic Uptake and Action. Williams and Wilkins, Philadelphia.

EndRenyi, L., InABI, T. and Kalow, W. (1976) Genetic study of amobarbital elimination based on its kinetics in twins. Clin. Pharmac. Ther. 20: 701-714.

Evans, G. H., Wilkinson, G. R. and Shand, D. G. (1973) The disposition of propranolol IV. A dominant role for tissue uptake in the dose-dependent extraction of propranolol by the perfused rat liver. J. Pharmac. exp. Ther. 186: $447-454$.

FADDY, J. M. (1976) General time-independent stochastic model. Biometrics 32: 443-444. 
GALEAZZI, R. L. and BENET, L. Z. (1976) Inappropriate use of the law of corresponding areas to calculate the time course of absorption for multicompartmental systems. J. Pharmack. Biopharm. 4: 43-56.

Garretr, E. R., Thomas, R. C., Wallach, D. P. and Alway, C. D. (1960) Psicofuranine: kinetics and mechanisms in vivo with the application of the analog computer. J. Pharmac. exp. Ther. 130: 106-118.

Garrett, E. R. and Lambert, H. J. (1966) Analog computer in drug dosage and formulation design. J. Pharm.

- SCi. 55: 626-634.

Garrett, E. R. (1973) Classical pharmacokinetics to the frontier. J. Pharmacok. Biopharm. 1: 341-361.

Gaudino. M. (1949) Kinetics of distribution of inulin between two body water compartments. Proc. Soc. exp. Biol. Med. 70: 672-674.

Gibaldi. M. (1969) Effect of mode of administration on drug distribution in a two-compartment open system. J. Pharm. Sci. 58: 327-331.

Gibaldi, M. and Feldman, S. (1969) Pharmacokinetic basis for the influence of route of administration on the area under the plasma concentration-time curve. J. Pharm. Sci. 58: 1477-1480.

Gibaldi, M., Nagashima, R. and Levy, G. (1969) Relationship between drug concentration in plasma or serum and amount of drug in the body. J. Pharm. Sci. 58: 193-197.

Gibaldi, M.. Boyes, R. N. and Feldman, S. (1971) Influence of first-pass effect on availability of drugs on oral administration. J. Pharm. Sci. 60: 1138-1340.

Gibaldi, M. and Weintraub. H. (1971) Some considerations in the determination and significance of biologic half-life. J. Pharm. Sci. 60: 624-626.

Gibaldi. M. and Perrier, D. (1975) Pharmacokinetics. Pharmacy and Related Subject Series, Swarbrick, J. (ed.), Marcel Dekker, New York.

Gibaldi. M. and Levy, G. (1976a) Pharmacokinetics in clinical practice I. Concepts. J. Am. med. Ass. 235: $1864-1867$

Gibaldi, M. and Levy. G. (1976b) Pharmacokinetics in clinical practice 2. Applications. J. Am. med. Ass. 235: $1987-1992$.

Gibaldi. M. (1977) Biopharmaceutics and Clinical Pharmacokinetics (2nd ed) Lea and Febiger, Philadelphia.

Gibaldi. M. and MCNamara. P. J. (1978) Apparent volumes of distribution and drug binding to plasma proteins and tissues. Europ. J. Clin. Pharmac. 13: 373-378.

Gibaldi, M., LeVY, G. and MCNamara, P. J. (1978) Effect of plasma protein and tissue binding on the biologic half-life of drugs. Clin. Pharmac. Ther. 24:1-4.

Gillette. J. R. (1968) Problems associated with the extrapolation of data from in vitro experiments to intact animals. In: Abstracts Simposia and Contributed Papers presented to the APhA Academy of Pharmaceutical Sciences at the 115th Annual Meeting of the American Pharmaceutical Association. Miami Beach, Florida. May 5-10. p. 16.

Gillettr, J. R. (1971) Factors affecting drug metabolism. Ann. N.Y. Acad. Sci. 179: 43-66.

Gillette, J. R. (1973) The importance of tissue distribution in pharmacokinetics. J. Pharmacok. Biopharm. 1: 497-520.

Gillette. J. R. and PANG. K. S. (1977) Theoretic aspects of pharmacokinetic drug interactions. Clin. Pharmac. Ther. 22: 623-639.

Gladtke. E. and von Huttingberg. H. M. (1974) Pharmacokinetik. Springer-Verlag. Berlin.

GLadtKe. E. (1979) Pharmacokinetics. An Introduction. Springer-Verlag. Berlin.

Goldstein, A. (1949) The interaction of drugs and plasma proteins. Pharmac. Rer. 1: 102-165.

GoreSKY. C. A. and BACH. G. G. (1970) Membrane transport and the hepatic circulation. Amm. N.Y. Acad. Sci. 170: $18-47$

Goresky, C. A., Bach, G. G. and Nadeat, B. E. (1973) On the uptake of materials by the intact liver. J. Clin. Imest. 52: $975-1009$

Gottschalk, I. A. and Merlis. S. (1976) Pharmacokinetics of Psychoactive Drugs: Blood Letels and Clinical Response. SP Medical \& Scientific Books. Jamaica. N.Y.

HagGaRD, H. W. (1924a) The absorption. distribution and elimination of ethyl ether I. The amount of ether absorbed in relation to the concentration inhaled and its fate in the body. J. Biol. Chem. 59: 737-751.

HagGard. H. W. (1924b) The absorption. distribution and elimination of ethyl ether II. Analysis of the mechanism of absorption and elimination of such a gas or vapour as ethyl ether. J. Biol. Chem. 59: $753-770$.

HAGGARD. H. W. (1924c) The absorption. distribution and elimination of ethyl ether III. The relation of the concentration of ether. or any similar volatile substance. in the central nervous system to the concentration in the arterial blood. and the buffer action of the body. J. Biol. Chem. 59:771-781.

Haggard. H. W. (1924d) The absorption. distribution and elimination of ethyl ether IV. Anesthetic tension of ether and the physiological response to various concentrations. J. Biol. Chem. 59: 783-793.

HaGgard. H. W. (1924e) The absorption. distribution and elimination of ethyl ether V. Importance of the volume of breathing during the induction and termination of ether anaesthesia. J. Biol. Chem. 59: 795-802.

Hamilton. W. F. Moore. J. W. Kinsman. J. M. and Spurling. R. G. (1931) Studies on the circulation IV. Further analysis of the injection method, and of changes in hemodynamics under physiological and pathological conditions. Am. J. Phisiol. 99: 534-551.

HarRis. P. A. and Riegelman. S. (1969) Influence of the route of administration on the area under the plasma concentration time curves. J. Pharm. Sci. 58: 71-75.

HART. H. E. (1955) Analysis of tracer experiments in non-conservative steady-state systems. Bull. math. Biophys. 17: $87-94$.

Himmelstein. K. J. and Bischoff. K. B. (1973a) Mathematical representation of cancer chemotherapy effects. $J$. Pharmacok. Biopharm. 1: 51-68.

Himmelstein. K. J. and Bischoff. K. B. (1973b) Models of ARA-C chemotherapy of L1210 leukemia in mice. $J$. Pharmacok. Biopharm. 1: 69-81.

Himmelstein. K. J. and LUtz. R. J. (1979) A review of the applications of physiologically based pharmacokinetic modeling. J. Pharmacok. Biopharm. 7: 127-145. 
Ho, N. F. H. and Higuchi, W. I. (1971) Quantitative interpretation of in vivo buccal absorption of $n$-alkanoic acids by the physical model approach. J. Pharm. Sci. 59: 537-541.

HoENiG, V. and SCHüCK, O. (1956) Hepatic clearance theory and applications. Rev. Czeck. Med. 2: 1-14.

Jacquez, J. A., Bellman, R. and Kalaba, R. (1960) Some mathematical aspects of chemotherapy II. The distribution of a drug in the body. Bull. math. Biophys. 22: 309-322.

JellifFe, R. W. (1968) An improved method of digoxin therapy. Ann. int. Med. 69: 703-717.

Jenne, J. W., MacDonald, F. M. and Mendoza, E. (1960) A study of the factors influencing the fall-off of intravenous isonizid and para-amino-salicylic acid. Conf. Chemotherapy Tuberculosis 19: 34-43.

Jokipis, S. G. and TURPEINEN, O. (1954) Kinetics of elimination of glucose from the blood during and after a continuous intravenous injection. J. clin. Invest. 33: 452-458.

JollifFeE, N. and SMith, H. W. (1931) The excretion of urine in the dog 1 . The urea and creatinine clearances on a mixed diet. Am. J. Physiol. 98 : 572-585.

Jusko, W. J. (1973) A pharmacodynamic model for cell cycle-specific chemotherapeutic agents. J. Pharmacok. Biopharm. 1: 175-200.

Jusko, W. J. and GRetch, M. (1976) Plasma and tissue protein binding of drugs in pharmacokinetics. Drug Metab. Rev. 5: 43-140.

Kalow, W. (1965) Pharmacogenetics, W. B. Saunders.

Kampman, J. P. (1979) Pharmacokinetics of propylthiouracil in man after intravenous infusion. J. Pharmacok. Biopharm. 5: 435-443.

Kaplan, S. A., Jack, M. L., Cotler, S. and Alexander, K. A. (1973) Utilization of area under the curve to elucidate the disposition of an extensively biotransformed drug. J. Pharmacok. Biopharm. 1: 201-216.

KeIDING, S. (1976) Hepatic elimination kinetics: The influence of hepatic blood flow on clearance determinations. Scand. J. clin. Lab. Invest. 36: 113-118.

Keiding, S., Johansen, S., Winkler, K., TOnnesen, K. and Tygstrup, N. (1976) Michaelis-Menten kinetics of galactose elimination by the isolated perfused pig liver. Am. J. Physiol. 230: 1302-1313.

Keiding, S. and Chiarantini, E. (1978) Effect of sinusoidal perfusion on galactose elimination kinetics in perfused rat liver. J. Pharmac. Exp. Ther. 205: 465-470.

Klotz, U., Avant, G. R., Hoyumpa, A., Schenker, S. and Wilkinson, G. R. (1974) The effects of age and liver disease on the disposition and elimination of diazepam in adult man. J. clin. Invest. 55: 347-359.

Kornhauser, D. M., Wood, A. J. J., Vestal, R. E., Wilkinson, G. R. and Shand, D. G. (1978) Biological determinants of propranolol disposition in man. Clin. Pharmac. Ther. 23: 165-174.

Koup, J. R., Schentag, J. J., Vance, J. W., Kuritzky, P. M., Pyszczynski, D. R. and Jusko, W. J. (1976) System for clinical pharmacokinetic monitoring of theophylline therapy. Am. J. Hosp. Pharm. 33: 949-956.

Krüger-ThIEMER, E. (1960a) Dosage schedules and pharmacokinetics in chemotherapy. J. Am. pharm. Assoc. Sci. Ed. 49: 311-313.

KRÜGER-THIEMER, E. (1960b) Functional relation between pharmacokinetic properties and dosage schedule of chemotherapeutic agents. Klin. Wschr. 38: 514-520.

KRÜGER-THIemer, E. and BÜNGer, P. (1961) Cumulation and toxicity as a result of wrong dosage schedule of sulfonamides. Arzneimittel-Forsch. $11: 867-874$.

KRÜGER-ThIEMER, E. and SChlender, B. (1963) Solution of chemotherapeutic problems using programmed computers II. The exact calculation of equation parameters and their confidence limits using the GaussNewton-Interaction procedures. Arzneimittel-Forsch. 13: 891-894.

Krüger-Thiemer, E., Dileer, W. and Bünger, P. (1966) Pharmacokinetic models regarding protein binding of drugs. Antimicrob. Agents Chemother. Washington 1965, pp. 183-191.

Kunka, R. L. and Mattocks, A. M. (1979) Nonlinear model for acetazolamide. J. Pharm. Sci. 68: 342-349.

KWAN, K. C. and TILL, A. E. (1973) Novel method for bioavailability assessment. J. Pharm. Sci. 62: 1494-1497.

KWAN, K. C., BONDI, J. V. and YEH, K. C. (1975) Bioavailability assessment under quasi- and nonsteady-state conditions I. Theoretical considerations. J. Pharm. Sci, 64: 1639-1642. II Study designs. ibid. 65: 512-517 (1976).

LAM, G. and CHIOU, W. L. (1979) Integrated equation to evaluate accumulation profiles of drugs eliminated by Michaelis-Menten kinetics. J. Pharmacok. Biopharm. 7: 227-232.

LAPP, C. (1948) Modes d'élimination des poisons. Définition de nouveaux coefficients toxicologiques. Annls. pharm. fr. 6: 150-165.

LapP, C. (1949) Calcul théorique des coefficients d'absorption. Fixation et transit tissulaire du salicylate de sodium chez des animaux. Annls. pharm. fr. 7: 278-288.

LAPP, C. (1950a) La cinétique de l'elimination des drogues. Acquisitions nouvelles de la théorie. Résultats numériques. Annls. pharm. fr. 8: 81-86.

LAPP, C. (1950b) Application de la cinétique d'élimination des drogues aux substances métaboliques. Cas de l'élimination experimentale de l'acide urique (methode de M. A. Quevauviller). Annls. pharm. fr. 8: 433-438.

LaPP, C. and Speiser, J. (1950) Hémikrèse et Protorrhée de l'arsenic. Annls. pharm. fr. 8: 803-812

LAPP, C. and LAPP, C.-F. (1952) Calcul des constantes d'élimination (Hémikrèse et Protorrhée) dan le cas des courbes incomplètes et applications à la clinique. Annls. pharm. fr. 10: 88-95.

LAPP, C. (1952) Hémikrèse et fluctuations biologiques d’élimination avec $\mathrm{S}, \mathrm{Hg}, \mathrm{As}, \mathrm{Cl}, \mathrm{Na}$. Annls. pharm. fr. 10 $561-575$.

LapP, C. and Nicolay, F. (1954) Etude du métabolisme d'un médicament par la cinétique des éliminations. Cas du Rubiazol C. Annls. pharm. fr. 12: 32-41.

Lapp, C. and Scius, G. (1954) Etude de l'élimination de la quinine. Hémikrèses et Protorrhées. Annls. pharm. fr. 12: 94-104.

LAPp. C. (1956a) Cinétique de l'élimination d'un dérivé soluble du Bismuth et comparaison avec les donnés pratiques. Annls. pharm. fr. 14: 439-448.

LAPP, C. (1956b) Elimination du Bismuth contenu dans un sel soluble: le bismuthotartrate de sodium absorbé per os. Annls. pharm. fr. 14: 448-456. 
LAX. L. C. and Wrenshall, G. A. (1953) Measurement of turnover rates in systems of hydrodynamic pools out of equilibrium. Nucleonics 11: 18-20.

Levy, G., Gumtow, R. H. and Turowskı, J. M. (1961) The effect of dosage form upon the gastrointestinal absorption rate of salicylates. Can. med. Ass. J. 85: 414-419.

LEVy. G. and NeLSON. E. (1965) Theoretical relationship between dose. elimination rate and duration of pharmacologic effect of drugs. J. Pharm. Sci. 54: 812 only.

LEVY, G. (1966) Kinetics of pharmacologic effects. Clin. Pharmac. Ther. 7: 362-372.

LeVy, G., GiBaldi. M. and Jusko, W. J. (1969) Multicompartment pharmacokinetic models and pharmacologic effects. J. Pharm. Sci. 58: 422-424.

LEVy, G., Tsuchira, T. and AMSEL, L. P. (1972) Limited capacity for salicyl phenolic glucuronide formation and its effect on the kinetics of salicylate elimination in man. Clin. Pharmac. Ther. 13: 258-268.

Levy, G. (ed.) (1974a) Clinical Pharmacokinetics, a Symposium. Academy of Pharmaceutical Sciences, American Pharmaceutical Association. Washington, D.C.

LEvr. G. and YACOBI. A. (1974b) Effect of plasma protein binding on elimination of warfarin. J. Pharm. Sci. 63: 805-806.

LEVY, G. (1976) Pharmacokinetic approaches to the study of drug interactions. Ann. N.Y. Acad. Sci. 281 : $24-39$.

LOO. J. C. K. and RIEGELMAN. S. (1968) A new method for calculating the intrinsic absorption rate of drugs. $J$. Pharm. Sci. 57: 918-928.

Ludden, T. M., Allen, J. P., Schneider. L. W. and Stavchansky, S. A. (1978) Rate of phenytoin accumulation in man: a simulation study. J. Pharmacok. Biopharm. 6: 399-415.

LUNDQUist, F, and Wolthers. M. (1953) The kinetics of alcohol elimination in man. Acta pharmac. tox. 14: 265-289.

Martin. A. and Doluisıo, J. T. (1977) Industrial bioavailability and pharmacokinetics. Guidelines, Regulations and Controls. Drug Dynamics Institute. College of Pharmacy, University of Texas, Austin. Texas.

MarTis, L. and LeVY. R. H. (1973) Bioavailability calculations for drugs showing simultaneous first-order and capacity-limited kinetics. J. Pharmacok. Biopharm. 1: 283-294.

Mayer. S.. Maickel. R. P. and Brodie, B. B. (1959) Kinetics of penetration of drugs and other foreign compounds into cerebrospinal fluid and brain. J. Pharmac. exp. Ther. 127: 205-211.

Mclean, A. J., McNamara. P. J.. DuSouich. P.. Gibaldi, M. and Lalka, D. (1978) Food, Splanchnic blood flow, and bioavailability of drugs subject to first-pass metabolism. Clin. Pharmac. Ther. 24: 5-10.

MCNamara, P. J.. Levy, G. and Gibaldi, M. (1979a) Effect of plasma protein and tissue binding on the time course of drug concentration in plasma. J. Pharmacok. Biopharm. 7: 195-206.

McNamara, P. J.. Slattery. J. T., Gibaldi. M. and Levy. G. (1979b) Accumulation kinetics of drugs with nonlinear plasma protein and tissue binding characteristics. J. Pharmacok. Biopharm. 7: 397-405.

Meffin. P. J.. Robert, E. W.. Winkle, R. A.. Harapat. S.. Peters. F. A. and Harrison, D. C. (1979) Role of concentration-dependent plasma protein binding in disopyramide disposition. J. Pharmacok. Biopharm. 7: 29-46.

Mrinick, D., Hochberg. M. and Oser. B. L. (1945) Physiological availability of the vitamins. J. Nutr. 30: $67-79$.

MFTZLER, C. M. (1969) NONLIN, a computer program for parameter estimation in nonlinear situations. Biostatistics Technical Report. 7292/69/7292/005. November 25. 1969. The Upjohn Company. Kalamazoo. MI 49001. U.S.A.

Michaelis. L. and Menten. M. L. (1913) Die Kinetik der Invertinwirking. Biochem. Z. 49: 333-369.

Moller. E.. MCINTOSH. J. F. and Van SLYKe. D. D. (1929) Studies of urea excretion. II Relationship between urine volume and the rate of urea excretion by normal adults. J. clin. Intest. 6: 427-434.

Nagashima. R.. O'Reilly. R. A. and Levy, G. (1969) Kinetics of pharmacologic effects in man: the anticoagulant action of warfarin. Clin. Pharmac. Ther. 10: 22-35.

NeLSON, E. and SChaldemose. I. (1959) Urinary excretion kinetics for evaluation of drug absorption. I. Solution rate limited and nonsolution rate of sulfaethylithiadiazole. $J$. Am. pharm. Assoc. Sci. Ed. 48: 489-495.

NeLSON. E. (1959) Influence of dissolution rate and surface area on tetracycline absorption. J. Am. pharm. Assoc. Sci. Ed. 48: 96-103.

NeLSON. E. (1961) Kinetics of drug absorption. distribution. metabolism and excretion. J. Pharm. Sci. 50: $181-192$.

Newburger. J.. Wagner. J. G. and Stavchansky. S. (1979) A method to predict infinity values for biexponential processes. J. Pharmacok. Biopharm. 7: 417-425.

Niazi, S. (1976) Volume of distribution as a function of time. J. Pharm. Sci. 65: 452-454.

Niazı, S. (1979) Texthook of Biopharmaceutics and Clinical Pharmacokinetics. Appleton-Century-Crofts (Prentice-Hall). New York, N.Y.

Nogami. H. and Matsuzawa. T. (1961) Studies of absorption and excretion of drugs. I. Kinetics of penetration of acidic drugs, salicyclic acid. through the intestinal barrier in vitro. Chem. pharm. Bull.. Tokyo 9: 532-540.

NotaRI. R. E. (1971) Biopharmaceutics and Pharmacokinetics. An Introduction (Ist edn.) Marcel Dekker. Inc., New York, USA.

Notari, R. E. (1975) Biopharmaceutics and Pharmacokinetics. An Introduction (2nd edn.) Marcel Dekker. New York.

Nǘesch. E. (1973) Proof of the general validity of Dost's law of corresponding areas. Eur. J. Clin. Pharmac. 6 33-43.

OiE. S. and Tozer. T. N. (1979) Effect of altered plasma protein binding on apparent volume of distribution. $J$. Pharm. Sci. 68: 1203-1205.

ONCHI. Y. and ASAO. Y. (1961) Absorption. distribution and elimination of di-ethyl ether in man. Br. J. Anaesth. 33: $544-548$.

Oppenheimer. J. H., Schwartz. H. L. and Surks. M. I. (1975) Determination of common parameters of iodothyronine metabolism and distribution in man by noncompartmental analysis. $J$. clin. Endocrin. of Metah. 41 : 319-324. 
OrME, B. M. and CUTLER, R. E. (1969) The relationship between kanamycin pharmacokinetics, distribution and renal function. Clin. pharmac. Ther. 10: 543-550.

Oser. B. L., Melnick, D. and Hochberg. M. (1945) Physiological availability of the vitamins: Study of methods for determining availability in pharmaceutical products. Ind. Engng. Chem. analyt. Edn. 17: 401-4!1.

Pagliaro, L. A. and Benet, L. Z. (1975) Critical compilation of terminal half-lives, percent excreted unchanged. and changes of half-life in renal and hepatic dysfunction for studies in humans with references. $J$. Pharmacok. Biopharm. 3: 333-352.

PANG, K. S. and GiLlette, J. R. (1978) A theoretical examination of the effects of gut wall metabolism, hepatic elimination, and enterohepatic recycling on estimates of bioavailability and hepatic blood flow. $J$. Pharmacok. Biopharm. 6: 355-367.

PANG, K. S. and Rowland. M. (1977) Hepatic clearance of drugs I. Theoretical consideration of a "well stirred" model and a 'parallel tube' model. Influence of hepatic blood flow, plasma and blood cell binding, and the hepatocellular enzymatic activity on hepatic drug clearance. J. Pharmacok. Biopharm. 5: 625-653.

PANG, K. S. and Rowland. M. (1977b) Hepatic clearance of drugs II. Experimental evidence for acceptance of the 'well-stirred' model over the 'parallel tube' model using lidocaine in the perfused rat liver in situ preparation. J. Pharmacok. Biopharm. 5: 655-680.

PANG, K. S. and Rowland. M. (1977) Hepatic clearance of drugs III. Additional experimental evidence supporting the 'well-stirred' model, using metabolite (MEGX) generated from lidocaine under varying hepatic blood flow rates and linear conditions in the perfused rat liver in situ preparation. $J$. Pharmacok. Biopharm. 5: 681-699.

PAPPER. E. M. and KITz, R. J. (eds) (1963) Uptake and Distribution of Anesthetic Agents. McGraw-Hill, New York.

Pedersen. P. V. (1978) General treatment of linear pharmacokinetics. J. Pharm. Sci. 67: 187-191.

PERL, W. (1960) A method for curve-fitting by exponential functions. Intern. J. Appl. Radiat. Isotopes. 8: 211-222.

Perrier, D. and Gibaldi. M. (1972) Influence of first-pass effect on the systemic availability of propoxyphene. J. clin. Pharmac. 12: 449-452.

Perrier, D.. Gibaldi, M. and Boyes, R. H. (1973a) Prediction of systemic availability from plasma level data after oral administration. J. Pharm. Pharmac. 25: 256-257.

Perrier, D., Ashley, J. J. and Levy, G. (1973b) Effect of product inhibition on kinetics of drug elimination. $J$ Pharmacok. Biopharm. 1 : 231-242.

Perrier, D. and Gibaldi, M. (1973) Relationship between plasma or serum concentration and amount of drug in the body at steady state upon multiple dosing. J. Pharmacok. Biopharm. 1: 17-22.

Plá Delfina, J. M. and Pozo Ojeda, A. (1974) Manual de Iniciacion la Biofarmacia (Farmacocinetica Aplicado), Faculty of Pharmacy, University of Barcelona, Spain.

Purdue, P. (1974) Stochastic theory of compartments: One and two compartment systems. Bull. Math. Biol. 36 $577-588$.

Rane, A., Wilkinson, G. R. and Shand, D. G. (1977) Prediction of hepatic extraction ratio from in vitro measurement of intrinsic clearance. J. Pharmac. Exp. Ther. 200: 420-424.

RASPE, E., Editor (1970) Advances in the Biosciences 5. Schering Workshop on Pharmacokinetics, Berlin, May 8-9. 1969. Pergamon Press. New York, U.S.A.

REINER. J. N. (1953) The study of metabolic turnover rates by means of isotopic traces I. Fundamental relations. Archs. Biochem. Biophys. 46: 53-79.

Rescigno. A. and Segré, G. (1966) Drug and Tracer Kinetics. Blaisdell, U.S.A.

Riegelman, S. and Cromwell, W. J. (1958) Kinetics of rectal adsorption I. Preliminary investigation into the absorption process. II. The absorption of anions. III. The absorption of undissociated molecules. J. Am. pharm. Ass. Sci. Ed. 47: 115-133.

Riegelman, S., LoO, J. C. K. and Rowland, M. (1968a) Shortcomings in Pharmacokinetic analysis by conceiving the body exhibit properties of a single compartment. J. Pharm. Sci. 57: 117-123.

Riegelman, S., Loo, J. and Rowland, M. (1968b) Concept of a volume of distribution and possible errors in evaluation of this parameter. J. Pharm. Sci. 57: 128-133.

Riegelman, S. and Rowland. M. (1973) Effect of route of administration on drug disposition. J. Pharmacok. Biopharm. 1: $419-434$.

Riggs, D. S. (1963) The Mathematical Approach to Physiological Problems. Williams \& Wilkins, Baltimore, M.D.

RitsChel. W. A. (ed.) (1977) Clinical Pharmacokinetics. Proceedings of an International Symposium held at Salzgitter-Ringelheim, Gustav Fisher Verlag, Stuttgart and New York.

Robertson, J. A. (1957) Theory and use of tracers in determining transfer rates in biological systems. Physiol. Ret. 37: 133-154.

Ronfeld. R. A. and Benet, L. Z. (1969) Volume terms in pharmacokinetics. J. Pharm. Sci. 58: 639-641.

RONFELD, R. A. and BENET, L. Z. (1977) Interpretation of plasma concentration time curve after oral dosing. $J$. Pharm. Sci. 66: 178-180.

Rowland, M. (1972) Influence of route of administration on drug availability. J. Pharm. Sci. 61 : $70-74$.

Rowland, M.. Benet, L. Z. and Graham, C. G. (1973) Clearance concepts in pharmacokinetics. J. Pharmacok. Biopharm. 1: 123-136.

Rowland. M. and Matin, S. B. (1973) Kinetics of drug-drug interactions. J. Pharmacok. Biopharm. 1: 553-567.

Russell. J. A. (1958) The use of isotopic tracers in estimating rates of metabolic reactions. Prospect. Biol. med. $1: 138-173$

Sapirstein, L. A., Vidt, D. G., Mandel. M. J. and Hanusek, G. (1955) Volumes of distribution and clearance of intravenously injected creatinine in the dog. Am. J. Physiol. 181: 330-336.

SCHANKER. L. S. (1960) On the mechanism of absorption of drugs from the gastrointestinal tract. $J$. mednl. pharm. Chem. 2: 343-359. 
SChiller, P. J. and Blchthal, F. (1958) Diphenylhydantoin and phenobarbital in serum of patients with epilepsy. Dan. med. Bull. 5: $161-163$.

SCHÖFELD. H. (ed.) (1978) Pharmacokinetics Antibiotics and Chemotherapy Vol. 25. S. Karger, New York, N.Y.

SCHOLAR, J. F. and CODE, C. F. (1954) Rate of absorption of water from stomach and small bowel of human beings. Gastroenterology 27: 565-577.

Sedman, A. J. and Wagner, J. G. (1974) Quantitative pooling of Michaelis-Menten equations in models with parallel metabolite formation paths. J. Pharmacok. Biopharm. 2: 149-160.

Segré. G. (1968) Kinetics of interaction between drugs and biological systems. /l Farmaco, Ed. Sci. 23: 907-918.

Shand, D. G., Branch, R. A.. Evans, G. H. Nies, A. S. and Wilkinson, G. R. (1973) The disposition of propranolol VII. The effects of saturable hepatic tissue uptake on drug clearance by the perfused rat liver. Drug. Metab. Dispos. 1: 679-686.

Shand, D. G., Kornhauser, D. M. and Wilkinson, G. R. (1975) Effects of route of administration and blood flow on hepatic drug elimination. J. Pharmac. exp. Ther. 195: 424432.

Shand, D. G., Cotham, R. H. and Wilkinson. G. R. (1976) Perfusion-limited effects of plasma drug binding on hepatic drug extraction. Life Sci. 19: 125 130.

Shaney, L.. Wasserman, L. R. and Gevistz. N. R. (1964) Representation of certain mammillary N-pool systems by two-pool models. Am. J. med. Electron. 3: 249-260.

Sheiner. L. B.. Rosenberg, B. and Marathe. V. V. (1977) Estimation of population characteristics of pharmacokinetic parameters from routine clinical data. J. Pharmacok. Biopharm. 5: 445-479.

ShiPley, R. A. and Clark, R. E. (1972) Tracer Methods for In vivo Kinetics: Theory and Applications, Academic Press. New York. N.Y.

Shore, P. A., Brodie. B. B. and Hogben. C. A. M. (1957) The gastric secretion of drugs. J. Pharmac. exp. Ther. $119,361-369$

SHORE. M. L. (1961) Biological applications of kinetic analysis of a two-compartment open system. J. appl. Physiol. 16: $771-782$.

SMOLEN, V. F. (1971) Determination of time course of in tivo pharmacological effects from in tivo drug release testing. J. Pharm. Sci. 60: $878-882$.

Smolin. V. F. and SChoenwald. R. D. (1971) Drug absorption analysis from pharmacological data I. Method and confirmation exemplified for the mydriatic drug tropicamide. J. Pharm. Sci. 60: 96-103 (1971).

SMOLEN. V. F. and WEIGAND. W. A. (1973) Drug bioavailability and pharmacokinetic analysis from pharmacological data. J. Pharmacok. Biopharm. 1 : 329-336.

SMOLEN, V. F. (1976a) Theoretical and computational basis for drug bioavailability determinations using pharmacological data. I. General considerations and procedures. J. Pharmacok. Biopharm. 4: 337-353.

SMOLEN. V. F. (1976b) Theoretical and computational basis for drug bioavailability determinations using pharmacological data. II. Drug input $\rightleftharpoons$ response relationships. J. Pharmacok. Biopharm. 4: 355-375.

Solomon. A. K. (1949) Equations for tracer experiments. J. clin. Incest. 28: 1297-1307.

Solomov. A. K. (1953) The kinetics of biological process. special problems connected with the use of tracers. Adt. Biol med. Phis. 3: 65.97

Stephenson, J. L. (1960) Theory of transport in linear biological system I. Fundamental intregal equation. Bull. Math. Biophys. 22: 1-17.

Suzlki. A.. Higuchl. W. I. and Ho. M. F. N. (1970a) Theoretical model studies of drug absorption and transport in the gastrointestinal tract 1. J. Pharm. Sci. 59: 644-651.

Suzuki, A.. Higuchi, W. I. and Ho. M. F. N. (1970b) Theoretical model studies of drug absorption and transport in the gastrointestinal tract II. J. Pharm. Sci. 59: 651 659.

Swarbrick. J. (ed.) (1973) Dosage Form Design and Bioarailahility. Current Concepts in the Pharmaceutical Sciences. Lea and Febiger. Philadelphia, PA.

Swintosky, J. V.. Robinson. M. J.. FlOzT, E. L. and FreF, S. M. (1957) Interpretation of human blood concentrations following oral doses. J. Am. pharm. Assoc. Sci. Ed. 46: 339-403.

TAIT. J. F. (1963) The use of isotopic steroid for the measurement of production rates in tiro. J. clin. Endocr. Metab. 23: 1285-1297.

TAYLOR. J. D. and WIEGAND. R. G. (1960) The analog computer and plasma drug kinetics. Clin. Pharmac. Ther. 3: $464-472$

TEORELL. T. (1937a) Kinetics of distribution of substances administered to the body $\mathrm{I}$. The extravascular modes of administration. Archs. int. Pharmacodin. Ther. 57: 205-255.

TEORFLL. T. (1937b) Kinetics of distribution of substances administered to the body II. The intravascular modes of administration. Archs. int. Pharmacody. Ther. 57: 226-240.

Teorell. T.. Dedrick. R. L. and Condliffe. P. E. (1974) Phamacology and Phamacokinetics Fogerty International Center Proceedings No. 20. Plenum. New York.

Till. A.. Benet. L. Z. and KWAN, K. C. (1974) An integrated approach to the pharmacokinetic analysis of drug absorption. J. Pharmacak. Biopharm. 2: 525-544.

Van Gemert. A. G. M. and Duyff. J. W. (1950) Optimal dosage of drugs. Acta physiol. pharmacol. neerl. 1: 256-278.

Van Rossum. J. M. (1968) Pharmacokinetics of accumulation. J. Pharm. Sci. 57: 2162-2165.

Van Rossum. J. M. (1971) Significance of pharmacokinetics for drug design and the planning of dosage regimens. In: Drug Design p. 501. Arievs. E. J. (ed.) Medicinal Chemistry Series Volume I. Academic Press, New York.

Valghan, D. P. and Trainok. A. (1975) Derivation of general equations for linear mammillary models when the drug is administered by different routes. J. Pharmacok. Biopharm. 3: 203-218.

Vaughav. D. P. and Tucker, G. T. (1976) General derivation of the ideal intravenous drug input required to achieve and maintain a constant plasma drug concentration. Theoretical application to lignocaine therapy. Europ. J. Clin. Pharmacol. 10: 433-440

Vaughan. D. P. (1977) A model-independent proof of Dost's law of corresponding areas. J. Pharmacok. Biopharm. 5: $271-277$ 
VAUGHAN, D. P. and HoPE, I. (1979) Applications of a recirculatory stochastic pharmacokinetic model: Limitations of compartmental models. J. Pharmacok. Biopharm. 7: 207-225.

WAGNer, J. G., CARPENTER, O. S. and Collins, E. J. (1960) Sustained action oral medication I. A Quantitative study of prednisolone in man, in the dog, and in vitro. J. Pharmac. exp. Ther. 129: 101-107.

WaGner, J. G. (1961) Biopharmaceutics: Absorption aspects. J. Pharm. Sci. 50: 359-387.

WaGner, J. G. and Nelson, E. (1963) Percent absorbed time plots derived from blood level and/or urinary excretion data. J. Pharm Sci. 52: 610-611.

Wagner, J. G., Northam. J. I., Alway, C. D. and Carpenter, O. S. (1965) Blood levels of drug at the equilibrium state after multiple dosing. Nature 207: 1301-1302.

WAGNER, J. G. (1967) A method of estimating relative absorption of a drug in series of clinical studies in which blood levels are measured after single and/or multiple doses. J. Pharm. Sci. 56: 652-653.

WAGNeR, J. G. (1968a) Kinetics of pharmacologic response I. Proposed relationship between response and drug concentration in the intact animal and man. J. Theor. Biol. 20: 173-201.

Wagner, J. G. (1968b) Pharmacokinetics. A. Rev. Pharmac. 8: 67-94.

WaGner, J. G. and Northam, J. I. (1968) Prediction of number of doses to reach equilibrium state. Abstracts of symposia and contributed papers presented to the APLA Academy of Pharmaceutical Sciences at the 115th annual meeting of the American Pharmaceutical Association, Miami Beach, Florida, May 5-10, 1968, p 59. Abstract No. 11.

Wagner. J. G. (1969) Pharmacokinetics. Notes Supplied by John G. Wagner, Ph.D., J. M. Richards Laboratory, Grosse Pointe Park, Michigan, pp. 80-83, $139-141$.

Wagner, J. G. (1971a) Biopharmaceutics and Relevant Pharmacokinetics, Drug Intelligence Publications, Hamilton. Illinois, U.S.A

WAGNER, J. G. (1971b) A new generalized nonlinear pharmacokinetic model and its implications. In Biopharmaceutics and Relevant Pharmacokinetics, pp. 302-317, Drug Intelligence Publications, Hamilton, IL.

Wagner, J. G. (1973a) Properties of the Michaelis-Menten equation and its integrated forms which are useful in pharmacokinetics. J. Pharmacok. Biopharm. 1: 103-121

WaGner, J. G. (1973b) A modern view of pharmacokinetics. J. Pharmacok. Biopharm. 1: 363-401.

W AGNeR, J. G. (1974) A safe method for rapidly achieving plasma concentration plateaus. Clin. Pharmac. Ther 16: $691-700$

WaGner, J. G. (1975a) Fundamentals of Clinical Pharmacokinetics (1st edn.) Drug Intelligence Publications, Inc.. Hamilton, Illinois.

WAGNeR, J. G. (1975b) Do you need a pharmacokinetic model, and, if so, which one? J. Pharmacok. Biopharm. 3: $457-478$.

WAGNER, J. G. (1976a) Linear pharmacokinetic models and vanishing exponential terms: Implications in pharmacokinetics. J. Pharmacok. Biopharm. 4: 395-425.

WAGNER, J. G. (1976b) Simple model to explain effects of plasma protein binding and tissue binding in calculated volumes of distribution, apparent elimination rate constants and clearances. Europ. J. Clin. Pharmacol. 10: 425-432.

WAGNER, J. G. (1976c) Rapid method of obtaining area under curve for any compartment of any linear pharmacokinetic model in terms of rate constánts. J. Pharmacok. Biopharm. 4: 281-285.

WAGNER, J. G. (1976d) Linear pharmacokinetic equations allowing direct calculations of many needed pharma. cokinetic parameters from the coefficients and exponents of polyexponential equations which have been fitted to the data. J. Pharmacok. Biopharm. 4: 443-467.

Wagner, J. G., Wilkinson, P. K., Sedman, A. J., Kay, D. R. and Weidler, D. J. (1976a) Elimination of alcohol from human blood. J. Pharm. Sci. 65: 152-154.

WaGner, J. G., Weidler, D. J. and Lin, Y.-J. (1976b) New method for detecting and quantitating pharmacokinetic drug-drug interactions applied to ethanol-propranol. Res. Comm. Chem. Path. Pharmac. 13: 9-18.

WAGNER, J. G. and AYRES, J. W. (1977) Bioavailability assessment: methods to estimate total area (AUC $0-\infty$ ) and total excreted $\left(A_{e}^{x}\right)$ and importance of blood and urine sampling scheme with application to digoxin J. Pharmacok. Biopharm. 5: 533-557.

WAGNER, J. G. (1978) Time to reach steady-state and prediction of steady-state concentrations for drugs obeying Michaelis-Menten elimination kinetics. J. Pharmacok. Biopharm. 6: 209-225.

Wheeler, L. A. and Sheiner, L. B. (1976) A generalized method for optimal dose computation. J. Pharmacok. Biopharm. 4: 487-497.

WIDMARK, E. and TANDRERG, J. (1924) Uber die bedingungen für die Akkumulation Indifferenter Narkoliken Theoretische Bereckerunger.) Biochem. Z. 147: 358-369.

WIDMARK, E. M. P. (1932) Die theoretischen Grundlagen und die praktische Verwendbzrkeit der gerichtlichmedizinischen Alkoholbestimmung, Berlin.

WiEgAND. P. G. and TAYLOR, J. D. (1960) Kinetics of plasma drug levels after sustained release dosage Biochem. Pharmac. 3: 256-263.

Wilkinson, G. R. (1975) Pharmacokinetics of drug disposition: Hemodynamic considerations. A. Rev. Pharmac. 15: 11-27.

Wilkinson, G. R. and Shand. D. G. (1975) A physiologic approach to hepatic drug clearance. Clin. Pharmac. Ther. 18: $377-390$.

Wilkinson, G. R. and SChENkER, S. (1976) Effects of liver disease on drug disposition in man. Biochem. Pharmac. 25: 2675-2681.

Wilkinson, P. K., Sedman, A. J., Sakmar, E., Kay, D. R. and Wagner, J. G. (1977) Pharmacokinetics of ethanol after oral administration in the fasting state. J. Pharmacok. Biopharm. 5: 207-224.

Williams, R. T. (1959) Detoxification Mechanisms: The Metabolism and Detoxification of Drugs, Toxic Substances, and Other Organic Compounds. Wiley, New York, N.Y.

Winkler, K., KeIDing, S. and Tygstup, N. (1973) Clearance as a quantitative measure of liver function. In The Liver: Quantitative Aspects of Structure and Functions pp. 144-155. Paumgartner. P. \& Presig. R., (eds) Karger. Basel. 
Winkler, K., Bass, L.. Keiding, S. and Tygstrup, N. (1974) The effect of hepatic perfusion on assessment of kinetic constants. In Alfred Benson Symposium VI: Regulation of Hepatic Metabolism pp. 797-807. LUNDQUist, F. \& TrgstruP, N. (eds). Munksgaard. Copenhagen.

Wong, D., Colburn, W. A. and Gibald, M. (1979) Fitting concentration-time data to biexponential equations. J. Pharmacok. Biopharm. 7: 97-100.

YACOBI, A. and LEVY. G. (1975) Comparative pharmacokinetics of coumarin anticoagulants XIV: Relationship between protein binding. distribution, and elimination kinetics of warfarin in rats. J. Pharm. Sci. 64: $1660-1664$

YACOBI, A. and LevY, G. (1977) Comparative pharmacokinetics of coumarin anticoagulants XXI: Effect of plasma protein binding on distribution kinetics of warfarin in rats. J. Pharm. Sci. 66: 567-572.

YamaOkA, K.. Nakagawa, T. and Uno. T. (1978) Statistical moments in pharmacokinetics. J. Pharmack. Biopharm. 6: 547-557. 